\title{
A magnetically responsive nanocomposite scaffold combined with Schwann cells promotes sciatic nerve regeneration upon exposure to magnetic field
}

\author{
This article was published in the following Dove Press journal: \\ International Journal of Nanomedicine \\ 24 October 2017 \\ Number of times this article has been viewed
}

\author{
Zhongyang Liu',* \\ Shu Zhu',* \\ Liang $\operatorname{Liu}^{2}, *$ \\ Jun $\mathrm{Ge}^{3,4, *}$ \\ Liangliang Huang' \\ Zhen Sun' \\ Wen Zeng ${ }^{5}$ \\ Jinghui Huang' \\ Zhuojing Luo'
}

'Department of Orthopedics, Xijing Hospital, Fourth Military Medical University, Xi'an, Shaanxi, ${ }^{2}$ Department of Orthopedics, No 16I Hospital of PLA, Wuhan, Hubei, ${ }^{3}$ Department of Orthopedics, No 323 Hospital of PLA, Xi'an, Shaanxi, ${ }^{4}$ Department of Anatomy, Fourth Military Medical University, Xi'an, Shaanxi, ${ }^{5}$ Department of Neurosurgery, Tangdu Hospital, Fourth Military Medical University, Xi'an, Shaanxi, People's Republic of China

*These authors contributed equally to this work

Correspondence: Jinghui Huang;

Zhuojing Luo

Department of Orthopedics, Xijing Hospital, Fourth Military Medical University, 169 Changle

West Road, Xi'an, Shaanxi 7I0032,

People's Republic of China

Tel/fax +86 2984775285

Email huangjh@fmmu.edu.cn;

zjluo@fmmu.edu.cn

\begin{abstract}
Peripheral nerve repair is still challenging for surgeons. Autologous nerve transplantation is the acknowledged therapy; however, its application is limited by the scarcity of available donor nerves, donor area morbidity, and neuroma formation. Biomaterials for engineering artificial nerves, particularly materials combined with supportive cells, display remarkable promising prospects. Schwann cells (SCs) are the absorbing seeding cells in peripheral nerve engineering repair; however, the attenuated biologic activity restricts their application. In this study, a magnetic nanocomposite scaffold fabricated from magnetic nanoparticles and a biodegradable chitosan-glycerophosphate polymer was made. Its structure was evaluated and characterized. The combined effects of magnetic scaffold (MG) with an applied magnetic field (MF) on the viability of SCs and peripheral nerve injury repair were investigated. The magnetic nanocomposite scaffold showed tunable magnetization and degradation rate. The MGs synergized with the applied MF to enhance the viability of SCs after transplantation. Furthermore, nerve regeneration and functional recovery were promoted by the synergism of SCs-loaded MGs and MF. Based on the current findings, the combined application of MGs and SCs with applied MF is a promising therapy for the engineering of peripheral nerve regeneration.
\end{abstract}

Keywords: peripheral nerve repair, magnetic nanoparticle, nanocomposite, magnetic field, Schwann cell, functional recovery

\section{Introduction}

The peripheral nervous system displays remarkable regenerative potential after injury. ${ }^{1}$ Although autologous nerve grafting is still considered the golden criterion and the most common therapy after peripheral nerve injury, its application is limited by the scarcity of available donor nerve, donor area morbidity, and neuroma formation. ${ }^{2,3}$ In recent decades, materials for engineering artificial nerves have become attractive treatments to repair peripheral nerve injuries, ${ }^{4}$ as they partially restore nerve regeneration by providing guidance cues for axonal regrowth. Many seeding cells and optimized nerve materials have been introduced to establish a tunable local milieu for regenerating axons at the spot of nerve deficiency and further improve nerve regeneration, ${ }^{5,6}$ thus holding great potential as a substitute for autologous nerves in nerve repair.

Schwann cells (SCs), the main gliocytes in the peripheral nerve system, are useful transplant seeding cells with positive functions in nerve repair due to their role in the organization of Büngner bands, potential to form myelin, and expression of multiple 
neurotrophic factors. ${ }^{7-10}$ Based on the above-mentioned considerations, the delivery of SCs to neural engineering biomaterials has recently been shown to be beneficial for nerve repair. ${ }^{11-15}$ However, attenuated biotic functions have been detected in $\mathrm{SC}$ cultures in vitro, which further dramatically restricts the application of SCs in peripheral nerve repair in vivo. ${ }^{16}$

In recent years, magnetic composites consisting of magnetic nanoparticles (MNPs) controlled with the applied magnetic field (MF) have been fabricated to enhance the biologic properties of cells and tissue engineering repair. A magnetic composite combined with an MF is capable of accelerating the proliferation rate of endothelial cells, facilitating the endothelial cells into capillary-like architectures, ${ }^{17}$ promoting cardiac cells to form myocardial tissue in vitro, ${ }^{18}$ stimulating human bone-derived mesenchymal stem cell proliferation, ${ }^{19}$ and improving osteogenesis in bone tissue repair in vivo. ${ }^{20}$ Moreover, an MNP-based magnetic nanocomposite hydrogel was synthesized for potential cartilage tissue engineering under MF. ${ }^{21}$ However, it is unclear whether the combination of magnetic composites and MF, especially the introduction of seeding cells, can be applied for promoting the peripheral nerve repair.

As shown in our previous study, magnetic nanocomposites composed of MNPs and chitosan-glycerophosphate combined with the applied MF upregulated the biotic functions of SCs, as well as the expression and secretion of multiple neurotrophic factors from SCs in vitro. ${ }^{22}$ However, the degradation of the magnetic scaffold (MG) is unclear, which is the essential factor required by all tissue engineering biomaterials for in vivo application. ${ }^{23}$ The variation of magnetization during the degradation time is unknown, which is a key element for the transplantation of the MG under exposure to MF in vivo. Furthermore, the efficiency of SCs combined with the magnetic nanocomposite scaffold exposed to MF on regenerating axons and promoting functional recovery after injury in vivo is still unknown.

In this study, we prepared a magnetic nanocomposite scaffold composed of MNPs and chitosan-glycerophosphate, which was loaded with SCs to form an SCs-loaded MG system. We first analyzed the structure and characterization of the MG. Then, a $15 \mathrm{~mm}$ long sciatic nerve gap in rats was bridged by this scaffold system. The distribution and viability of the SCs within the scaffolds upon exposure to MF were examined after surgery. Moreover, the efficiency of the SCs-loaded magnetically responsive scaffold on regenerating axons and in promoting functional neurologic recovery was further evaluated following exposure to MF.

\section{Materials and methods Preparation of the magnetically responsive nanocomposite scaffold}

MNPs were synthesized using a previously described approach. ${ }^{24}$ Briefly, 2.728 g of $\mathrm{KNO}_{3}(\geq 99 \%$; Sigma-Aldrich, St Louis, MO, USA) and $0.972 \mathrm{~g}$ of $\mathrm{NaOH}$ ( $\geq 98 \%$; SigmaAldrich) were intermixed and then solubilized in $270 \mathrm{~mL}$ of deionized water in a $\mathrm{N}_{2}$ bubble bath. Then, during $4 \mathrm{~h}$ of $\mathrm{N}_{2}$ flow, $30 \mathrm{~mL}$ of a $0.01 \mathrm{M} \mathrm{H}_{2} \mathrm{SO}_{4}$ ( $\geq 98 \%$; Sigma-Aldrich) solution including $0.616 \mathrm{~g}$ of $\mathrm{FeSO}_{4} \cdot 7 \mathrm{H}_{2} \mathrm{O}$ ( $\geq 99 \%$; SigmaAldrich) was mixed to the solution that had previously been prepared with constant stirring. When the precipitation was completed, an additional 20 min of $\mathrm{N}_{2}$ flow would have elapsed, and the product was heated to a higher temperature at $90^{\circ} \mathrm{C}$ for an additional $24 \mathrm{~h}$. In the end, the product was cooled down to ambient temperature. The black products were segregated by magnetic decantation and later bathed in deionized water several times to rinse all the residuary impurities. The morphology, mean particle size, and distribution of MNPs were observed using transmission electron microscopy (TEM; TECNAI Spirit; FEI, Hillsboro, OR, USA). The crystal pattern of MNPs was confirmed using X-ray diffraction (Rigaku Miniflex, Tokyo, Japan). The magnetization of MNPs was detected using a vibrating sample magnetometer (665; Lake Shore Cryotronics, Westerville, OH, USA).

The magnetically responsive scaffold was prepared using a previously described method. ${ }^{22}$ Briefly, 200 $\mathrm{mg}$ of chitosan (molecular weight $>310 \mathrm{kDa}$, SigmaAldrich) and $10 \mathrm{~mL}$ of a $0.1 \mathrm{M}$ acetic acid solution were intermixed together to form a chitosan-acetic acid solution. The $\beta$-glycerophosphate salt solution, which was formed by intermixing $2 \mathrm{~mL}$ of PBS and 1,000 $\mathrm{mg}$ of $\beta$-glycerophosphate salt (Sigma-Aldrich), was added dropwise to the chitosan-acetic acid solution in an ice bath. The homogeneous solution obtained was transparent, with a $\mathrm{pH}$ of 7.03. The chitosan-glycerophosphate intermixture was later frozen at $-80^{\circ} \mathrm{C}$ for $48 \mathrm{~h}$ and freeze-dried for an additional $36 \mathrm{~h}$. The intermixture and previously prepared MNPs were sterilized with ethylene dioxide at $37^{\circ} \mathrm{C}$. Then, $10 \mathrm{~mL}$ of deionized water was added to $200 \mathrm{mg}$ of the chitosan-glycerophosphate freeze-dried powder to prepare the chitosan-glycerophosphate solution, and then $20 \mathrm{mg}$ of MNPs was mixed into the above solution with strong intermixing in an ice bath for $4 \mathrm{~h}$. Then, the intermixture was transferred to a customized module $(2.0 \mathrm{~mm}$ in diameter, $25 \mathrm{~mm}$ in length) to fabricate the $\mathrm{MG}$, and the weight ratio of MNPs was $10 \%$ in the magnetic nanocomposite, which was optimally prescreened in our previously study. ${ }^{22}$ 
The chitosan-glycerophosphate solution without MNPs was used as a nonmagnetic scaffold (non-MG).

\section{Magnetic measurements of the magnetic scaffold}

The magnetic attraction of the MG was assessed by a standard magnet. The magnetization of the $\mathrm{MG}$ at low field (34 Oe) was performed using a YSZ 01C/02C susceptometer (Sartorius Mechatronics, Muggiò, Italy). The high-field magnetization of the MG was calibrated using a vibrating sample magnetometer.

\section{Morphologic characterization of the magnetic scaffold}

The general appearance of the MG was observed with a stereomicroscope. The morphologic structure of the MG was determined using scanning electron microscope (Hitachi Ltd., Tokyo, Japan) at $5 \mathrm{kV}$. The scaffolds had been gold sputter-coated beforehand and observed in a partial vacuum. In addition, the morphologic characterization of the non-MG was also performed as described earlier.

\section{Degradation test of the magnetic scaffold}

Weight loss of the MG was observed by the degradation test. The sterilized scaffolds were immersed in sterilized PBS for different periods of time. At each week of the testing period after incubation with PBS, the scaffolds were lyophilized again. The weight and the magnetization of the freeze-dried scaffolds were measured and recorded.

\section{In vivo biocompatibility of the magnetic scaffold}

The prospective application of the MG for sciatic nerve regeneration suggested that this biomaterial would be sutured intimately with nerves. Therefore, the study of the biomaterial-tissue response of the MG with the sciatic nerve was performed. In detail, the non-MGs and the MGs (2.0 $\mathrm{mm}$ in diameter, $15 \mathrm{~mm}$ in length) were sterilized and disinfected for 30 min under ultraviolet ray, and then incubated in $0.9 \%$ saline solution before implantation. All animal procedures were performed under the approval and guidance of the Institutional Ethical Committee of Fourth Military Medical University. Twenty-four male adult Sprague Dawley rats weighing 220-250 g (obtained from the Laboratory Animal Center of Fourth Military Medical University) were randomly divided into two groups, that is, the non-MG group and the MG group. All rats were anesthetized with a $3.6 \%$ chloral hydrate solution $(10 \mathrm{~mL} / \mathrm{kg}$, intraperitoneal). Under sterile conditions, the exposure of the left sciatic nerve of the animal was performed under an operating microscope and the scaffolds were placed on top of the sciatic nerve. The muscle layer was then stitched with 4-0 sutures and the skin was closed using 6-0 sutures. After surgery, the rats had access to food and water ad libitum. The animals were sacrificed at 1 and 12 weeks postimplantation. Tissue samples of intact implants were harvested en bloc for histologic analysis. The samples were immersed in $4 \%$ paraformaldehyde in $0.1 \mathrm{M}$ PBS for 2 weeks at $4^{\circ} \mathrm{C}$. Then, five longitudinal sections per specimen were prepared and subjected to hematoxylin and eosin staining to evaluate the biocompatibility of the MG. Histology images were photographed using a light microscope (AH3; Olympus Corporation, Tokyo, Japan).

\section{MF stimulation system}

The MF stimulation system consisted of an arc-shaped magnet twined with enamel-coated copper wire $(1.00 \mathrm{~mm}$ diameter) and an MF producer to generate MFs with a proper frequency of 0-100 Hz and an intensity of 0-20 mT. The MF producer (GHY-III, patent ZL02224739.4; Fourth Military Medical University, Xi'an, China) was connected to the magnet to generate an open-circuit wave shape of MF. A Gaussmeter (Model 455 DSP; Lake Shore Cryotronics) was used to measure the accuracy of the MF output. A small $2 \Omega$ resistor was properly placed in series connection, and the output frequency and the waveform were visualized on an oscillograph (6000 series; Agilent Technologies, Santa Clara, CA, USA). The frequency of MF was set to $50 \mathrm{~Hz}$, as applied in previous experiments. ${ }^{25-27}$

\section{SCs' culture and preparation}

SCs were isolated and purified following the previously described protocol. ${ }^{28}$ All the experiments were undertaken in conformity with the Guide for the Care and Use of Laboratory Animals (National Institutes of Health publication No 85-23, revised 1985). ${ }^{29}$ In brief, the sciatic and brachial plexus nerves of 2-day-old Sprague Dawley rats (obtained from the Experimental Animal Center of Fourth Military Medical University) were severed, and SCs were harvested and further sorted out from fibroblasts by adding a combination of rabbit complement and fibronectin-specific antibody. The purity of SCs was confirmed by double immunofluorescent staining with antibodies against Sox-10 (green, 1:250; Abcam, Cambridge, MA, USA) and S-100 (red, 1:250; Abcam). The number of Sox-10and S-100-positive cells and 4',6-diamidino-2-phenylindolelabeled cells was compared. SCs were incubated in 
DMEM/nutrient mixture F-12 (Thermo Fisher Scientific, Waltham, MA, USA) consisting of $15 \%$ fetal bovine serum (Thermo Fisher Scientific), antibiotics $(100 \mu \mathrm{g} / \mathrm{mL}$ streptomycin and $100 \mathrm{UI} / \mathrm{mL}$ penicillin), $20 \mu \mathrm{g} / \mathrm{mL}$ bovine pituitary extract (Biomedical Technologies, Stoughton, MA, USA), and $2 \mu \mathrm{M} / \mathrm{mL}$ forskolin (Sigma-Aldrich) at $37^{\circ} \mathrm{C}$ in a humidified, $5 \% \mathrm{CO}_{2}$ atmosphere.

\section{Procedure for preparing the SCs-loaded magnetic scaffold}

The MG fabricated previously was cut into cylinders (15 $\mathrm{mm}$ in length). The mixed scaffolds used in this experiment were composed of the magnetically responsive scaffold and SCs. The SCs-loaded MG system was constructed and then prepared for surgery.

\section{Animals, surgical operations, and experimental design}

All animal procedures were performed under the approval and guidance of the Institutional Ethical Committee of Fourth Military Medical University. A total of 306 male adult Sprague Dawley rats weighing 220-250 g (obtained from the Laboratory Animal Center of Fourth Military Medical University) were randomly divided into five groups as shown in Table 1. All animals were anesthetized with a $3.6 \%$ chloral hydrate solution $(10 \mathrm{~mL} / \mathrm{kg}$, intraperitoneal). Under a sterile environment, the exposure of the left sciatic nerve of the animal was performed under an operating microscope. Then, a $15 \mathrm{~mm}$ long gap was made in the sciatic nerve. In the autograft group, the amputated sciatic nerve was reversed $180^{\circ}$ and resutured. In the other four

Table I Number of animals per group

\begin{tabular}{|c|c|c|c|c|c|}
\hline $\begin{array}{l}\text { Experimental time point } \\
\text { after surgery }\end{array}$ & Autograft group & MG group & MG+MF group & MG+SCs group & MG + SCs + MF group \\
\hline \multicolumn{6}{|l|}{3 days } \\
\hline Cell viability analysis & - & - & - & $\begin{array}{l}6 \text { (No 89/II3/I29/ } \\
\text { 164/207/266) }\end{array}$ & $\begin{array}{l}6(\text { No I7/200/223/ } \\
267 / 269 / 304)\end{array}$ \\
\hline \multicolumn{6}{|l|}{7 days } \\
\hline Cell viability analysis & - & - & - & $\begin{array}{l}6 \text { (No 43/47/II4/ } \\
285 / 288 / 298)\end{array}$ & $\begin{array}{l}6 \text { (No I39/169/244/ } \\
258 / 295 / 299)\end{array}$ \\
\hline \multicolumn{6}{|l|}{14 days } \\
\hline Cell viability analysis & - & - & - & $\begin{array}{l}6 \text { (No } 8 / 119 / 122 / \\
136 / 150 / 219)\end{array}$ & $\begin{array}{l}6 \text { (No 4/40/77/ } \\
243 / 282 / 286)\end{array}$ \\
\hline \multicolumn{6}{|l|}{4 weeks } \\
\hline $\begin{array}{l}\text { Axonal regeneration and } \\
\text { functional recovery evaluation }{ }^{\mathrm{a}}\end{array}$ & $\begin{array}{l}6(\text { No } 84 / 130 / 135 / \\
160 / 242 / 301)\end{array}$ & $\begin{array}{l}6(\text { No } 27 / 68 / 91 / \\
100 / 232 / 278)\end{array}$ & $\begin{array}{l}6(\text { No } 38 / 70 / 82 / \\
87 / / 37 / / 56)\end{array}$ & $\begin{array}{l}6(\text { No } 7 / 106 / 157 / \\
235 / 240 / 300)\end{array}$ & $\begin{array}{l}6 \text { (No 49/58/I46/ } \\
178 / 256 / 302)\end{array}$ \\
\hline FG retrograde tracing analysis & $\begin{array}{l}6(\text { No II } 18 / 175 / 188 / \\
205 / 206 / 306)\end{array}$ & $\begin{array}{l}6(\text { No } 73 / 95 / 97 \mid \\
\text { |82/245/255) }\end{array}$ & $\begin{array}{l}6 \text { (No 36/67/I7I/ } \\
2 \mid 4 / 234 / 28 I)\end{array}$ & $\begin{array}{l}6 \text { (No 30/7I/93/ } \\
227 / 25 \mathrm{I} / 287)\end{array}$ & $\begin{array}{l}6(\text { No } 79 / 155 / \mid 62 / \\
180 / 261 / 296)\end{array}$ \\
\hline $\begin{array}{l}\text { Immunohistochemistry } \\
\text { assessment }\end{array}$ & $\begin{array}{l}6 \text { (No } 19 / \mid 16 / 132 / \\
138 /|5| / \mid 58)\end{array}$ & $\begin{array}{l}6 \text { (No 52/96/103/ } \\
197 / 199 / 204)\end{array}$ & $\begin{array}{l}6 \text { (No I3/I5/I45/ } \\
149 / 189 / 294)\end{array}$ & $\begin{array}{l}6(\text { No } 22 / 54 / 85 / \\
102 / 230 / 283)\end{array}$ & $\begin{array}{l}6(\text { No } 39 / 62 / 72 / \\
165 / 187 / 226)\end{array}$ \\
\hline \multicolumn{6}{|l|}{8 weeks } \\
\hline $\begin{array}{l}\text { Axonal regeneration and } \\
\text { functional recovery evaluation }\end{array}$ & $\begin{array}{l}6 \text { (No 3I/90/I67/ } \\
202 / 221 / 224)\end{array}$ & $\begin{array}{l}6(\text { No } 5 / 16 / 32 / \\
107 / 239 / 246)\end{array}$ & $\begin{array}{l}6 \text { (No 69/76/109/ } \\
174 / 179 / 190)\end{array}$ & $\begin{array}{l}6 \text { (No 42/I05//83/ } \\
212 / 254 / 273)\end{array}$ & $\begin{array}{l}6(\text { No I I /28/37/ } \\
101 / 220 / 237)\end{array}$ \\
\hline FG retrograde tracing analysis & $\begin{array}{l}6 \text { (No I/23/I I5/ } \\
\text { I59/247/292) }\end{array}$ & $\begin{array}{l}6 \text { (No } 25 / 75 / \mid 34 / \\
191 / 259 / 297)\end{array}$ & $\begin{array}{l}6(\text { No } 98 / 184 / 203 / \\
238 / 291 / 305)\end{array}$ & $\begin{array}{l}6 \text { (No I8/21/60/ } \\
\mid 27 / 248 / 289)\end{array}$ & $\begin{array}{l}6 \text { (No 92/I24/ } \\
|26 / 208 / 27| / 284)\end{array}$ \\
\hline $\begin{array}{l}\text { Immunohistochemistry } \\
\text { assessment }\end{array}$ & $\begin{array}{l}6 \text { (No } 59 / 210 / 225 / \\
233 / 265 / 270)\end{array}$ & $\begin{array}{l}6 \text { (No 34/48/121/ } \\
198 / 211 / 217)\end{array}$ & $\begin{array}{l}6(\text { No } 35 / 56 / 123 / \\
153 / 163 / 280)\end{array}$ & $\begin{array}{l}6 \text { (No 4l/66//93/ } \\
209 / 260 / 262)\end{array}$ & $\begin{array}{l}6(\text { No } 53 / 57 / 63 / \\
86 / 154 / 213)\end{array}$ \\
\hline \multicolumn{6}{|l|}{ I 2 weeks } \\
\hline $\begin{array}{l}\text { Axonal regeneration and } \\
\text { functional recovery evaluation }\end{array}$ & $\begin{array}{l}6(\text { No }|10 /||| 2 / \mid 40 / \\
|48 /| 18 \mid / 277)\end{array}$ & $\begin{array}{l}6(\text { No } 6 / 99 / 141 / \\
252 / 272 / 275)\end{array}$ & $\begin{array}{l}6(\text { No } 33 / 61 / / 08 / \\
128 / / 52 / 185)\end{array}$ & $\begin{array}{l}6(\text { No } 9 / 29 / 78 / \\
172 / 192 / 276)\end{array}$ & $\begin{array}{l}6(\text { No } 64 / 83 / 173 / \\
|94 / 2| 8 / 253)\end{array}$ \\
\hline FG retrograde tracing analysis & $\begin{array}{l}6 \text { (No 46/55/|3|/ } \\
2 \mid 6 / 250 / 293)\end{array}$ & $\begin{array}{l}6 \text { (No I4/26/166/ } \\
228 / 236 / 264)\end{array}$ & $\begin{array}{l}6 \text { (No 45/5 I/8 |/ } \\
\mid 44 / 195 / 215)\end{array}$ & $\begin{array}{l}6 \text { (No I0/24/I47/ } \\
\text { I68/222/290) }\end{array}$ & $\begin{array}{l}6 \text { (No } 20 / 80 / / 43 / \\
23 I / 257 / 303)\end{array}$ \\
\hline $\begin{array}{l}\text { Immunohistochemistry } \\
\text { assessment }\end{array}$ & $\begin{array}{l}6 \text { (No 3/I2/186/ } \\
\text { 196/249/268) }\end{array}$ & $\begin{array}{l}6 \text { (No 50/94/I6I/ } \\
229 / 263 / 279)\end{array}$ & $\begin{array}{l}6 \text { (No 65/74/II7/ } \\
|42 / 24| / 274)\end{array}$ & $\begin{array}{l}6(\text { No } 44 / 104 / 120 / \\
125 / / 70 / 176)\end{array}$ & $\begin{array}{l}6 \text { (No } 2 / 88 / I|| \mid \\
|33 /| 77 / 201)\end{array}$ \\
\hline Total number & 54 & 54 & 54 & 72 & 72 \\
\hline
\end{tabular}

Note: ${ }^{a}$ Axonal regeneration and functional recovery evaluation involving morphometric assessment of sciatic nerve, sensorimotor recovery assessment, and weighting and histologic examination of target muscles.

Abbreviations: FG, Fluoro-Gold; MF, magnetic field; MG, the rats were bridged with the magnetic scaffold; MG+MF, the rats were bridged with the magnetic scaffold and under MF exposure after surgery; MG+SCs, the rats were bridged with the Schwann cells-loaded magnetic scaffold; MG+SCs+MF, the rats were bridged with the Schwann cells-loaded magnetic scaffold and under MF after surgery; SCs, Schwann cells. 
groups, the nerve scaffold was used to bridge the nerve gap, and then, both the proximal and distal nerve stumps were sutured with three perineural $10 / 0$ prolene sutures. The skin was then stitched with 6-0 sutures in all groups. After operation, the rats were transferred back to cages and were fed with food and water ad libitum. The MF exposure groups were exposed to an applied MF at $2 \mathrm{mT}$ for $2 \mathrm{~h}$ as previously performed, at the same time each day after surgery. Specifically, during the MF exposure time postoperation, the animals were fixed in a customized stable apparatus, and then the anarc-shaped magnet twined with copper wire was set properly at the MF stimulation area which was above the operative region of the bridged scaffold, making the orientation of the MF applied in the MG from proximal to distal, because the effect of the MF on the MG is largely dependent on the field direction. The rats bridged with the MG represented the MG group. The rats bridged with the MG and under MF exposure after surgery represented the $\mathrm{MG}+\mathrm{MF}$ group. The rats bridged with the SCs-loaded MG represented the MG+SCs group. The rats bridged with the SCs-loaded MG and under MF after surgery represented the $\mathrm{MG}+\mathrm{SCs}+\mathrm{MF}$ group.

\section{Analysis of cell viability after surgery}

At 3, 7, and 14 days after surgery, the rats $(n=6$, at every point in time of each group) were anesthetized prior to an intracardial perfusion with $0.1 \mathrm{M}$ PBS followed by ice-cold $4 \%$ paraformaldehyde buffer. Then, the grafts were harvested and sectioned. Serial $25 \mu \mathrm{m}$ thick longitudinal sections of the grafts were immediately transferred onto slides and then stained by using a Live/Dead cell staining kit (BioVision, Milpitas, CA, USA). Live cells were labeled with a green fluorescent dye Live-Dye ${ }^{\mathrm{TM}}$, for which the excitation/emission peak was at 488/518 nm, and dead cells were labeled with a red fluorescent dye propidium iodide, for which the excitation/emission peak was at 488/615 nm. The bicolor labeling was visualized, and images were captured with a fluorescence microscope (DM6000; Leica Microsystems, Wetzlar, Germany). The cell viability was confirmed by counting from six randomized fields of interest, and then expressed as the average percentage of cell survival (live cells/total cells $\times 100 \%$ ).

\section{Morphometric evaluation of axonal regeneration}

At 4, 8, and 12 weeks postoperation, the regenerative nerves were quickly harvested and fixed in 3\% glutaraldehyde for $2 \mathrm{~h}$ and postfixed in $1 \%$ osmium tetroxide for $2 \mathrm{~h}$. After washing and dehydration, the specimens were embedded in epoxy resin media. Then, the distal portions of the regenerative nerves were cut into $1 \mu \mathrm{m}$ of semi-thin and $50 \mathrm{~nm}$ of ultrathin sections transversely. The semi-thin sections were dyed by $1 \%$ toluidine blue and observed under a light microscope (AH3; Olympus Corporation). The ultrathin sections were dyed by uranyl acetate and lead citrate and were observed by TEM. Six semi-thin sections and six ultrathin sections were randomly selected at each portion of the regenerative nerve for the quantitative analysis. The total area of regenerated nerves and the total number of myelinated axons were calculated for each semi-thin section. The mean diameter of the nerve fibers and the G-ratio (the axon-to-fiber diameter ratio) were calculated and assessed for each ultrathin section.

\section{Double immunofluorescence staining of the regenerated nerves and axons}

Twelve weeks after surgery, serial longitudinal sections (thickness of $10 \mu \mathrm{m}$ ) of the middle portions of the grafted segments ( $\sim 9.0 \mathrm{~mm}$ long) were cut on a cryostat. The sections were allowed to be incubated with the rabbit anti-S-100 monoclonal antibody $(1: 250$; Abcam) and the mouse antiNF200 monoclonal antibody (1:250; Abcam) at $4^{\circ} \mathrm{C}$ for $12 \mathrm{~h}$. Next, the goat anti-rabbit IgG TRITC (1:250; Abcam) and the goat anti-mouse IgG FITC (1:250; Abcam) secondary antibodies were used to probe the primary antibodies for $1 \mathrm{~h}$ at $37^{\circ} \mathrm{C}$. For the observation of the double immunofluorescence staining, six slides were randomly selected from each group, and each section was rinsed, mounted on glycerincoated slides, and cover slipped. The sections were analyzed under a fluorescence microscope (DM6000; Leica).

\section{Sensorimotor recovery analysis}

At 4, 8, and 12 weeks postoperation, the locomotor function recovery was evaluated by the walking track test and the assessment of the sciatic functional index (SFI).$^{30}$ Briefly, the rats' hind paws were dipped in red nontoxic dye and the animals were made to walk across a $100 \times 9 \times 6 \mathrm{~cm}$ narrow wooden corridor. Six measurable footprints were then collected and photographed, and the SFIs were measured using the following equation: SFI $=109.5 \times($ ETS - NTS $)$

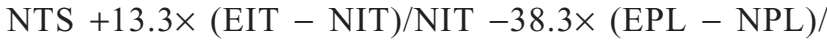
NPL -8.8, where TS stands for toe spread (distance between the first and the fifth toe), IT stands for intermediary toe spread (distance between the second and the fourth toe), and PL stands for print length (distance between the heel and the top of the third toe). NTS, NIT, and NPL stand for the TS, IT, and PL measured from the nonsurgical foot, respectively. 
ETS, EIT, and EPL stand for the TS, IT, and PL measured from the surgical foot, respectively. The value of SFI that oscillated around 0 indicated normal nerve function or total nerve recovery, whereas the SFI score of -100 represented total dysfunction.

After SFI analysis, the sensory nociceptive function recovery of the injured hindlimb was performed using the plantar test. Briefly, the mice were placed on a transparent Plexiglas box and radiant heat was used to stimulate the left hind paw. The latency time in response to a hind paw lick or shake/jump was recorded and used as a nociception index. The testing was performed only once per time point in order to prevent sensitization. The thermal stimulus was stopped to prevent heat damage if the animals were nonresponsive for $30 \mathrm{~s}$.

\section{Retrograde Fluoro-Gold (FG) labeling}

At 4, 8, and 12 weeks postoperation, FG retrograde tracing was undertaken and the back-labeled cells were calculated. Briefly, the area of sciatic nerve was exposed, and the nerve $5 \mathrm{~mm}$ distal to the distal end of the scaffold was crushed with a pair of forceps three times for $15 \mathrm{~s}$ with a $15 \mathrm{~s}$ interval to injure the regenerated axons, and then, intraneural injection of $5.0 \mu \mathrm{L} 4 \%$ FG (Biotium, Hayward, CA, USA) was administered into the nerve trunk at the spot described earlier. Finally, the incision was sutured. The animals were kept routinely in cages for 1 week. After 1 week, 4\% (w/v) paraformaldehyde in $0.1 \mathrm{M}$ PBS was intracardially perfused into the rats under anesthesia. The L4-6 level of lumbar spinal cord and the corresponding dorsal root ganglia (DRG) were harvested and then sectioned within a cryostat. Serial $16 \mu \mathrm{m}$ thick longitudinal sections of the DRG and $25 \mu \mathrm{m}$ thick transverse sections of the spinal cord were mounted on glass slides and observed and captured using a fluorescence microscope (DM6000; Leica). Both the amount of FG-positive motoneurons from the spinal cord and sensory neurons from the DRG were calculated.

\section{Weighing target muscles and histologic analysis}

Twelve weeks after surgery, the operational and contralateral side gastrocnemius muscles were harvested and weighted, respectively. Muscle weights were normalized to the contralateral side to account for individual differences between animals. Then, the muscles were immersed in $4 \%$ paraformaldehyde in $0.1 \mathrm{M}$ PBS for 2 weeks at $4{ }^{\circ} \mathrm{C}$. Then, five cross sections (thickness of $50 \mu \mathrm{m}$ ) per specimen were prepared and subjected to Masson's trichrome staining. Next, the sections were photographed using a light microscope (AH3; Olympus) to calculate the muscles' area. For the quantitative analysis, six randomly selected fields in each section were counted. The quantification of diameters of muscle fibers was performed using the ImageJ software (NIH, Bethesda, MD, USA).

\section{Microvessel density (MVD) analysis}

Twelve weeks postoperation, $10 \mu \mathrm{m}$ thick cross sections of the middle portions of the regenerative nerve were prepared and the MVD was quantified using an immunofluorescence staining. Briefly, the specimens were dyed with a rabbit antiCD34 antibody (1:250; Abcam) for $24 \mathrm{~h}$ at $4^{\circ} \mathrm{C}$. Next, a goat anti-rabbit IgG FITC (1:250; Abcam) was added to probe the primary antibody for $2 \mathrm{~h}$ at $37^{\circ} \mathrm{C}$. For the quantitative evaluation, six randomized fields of interest were then chosen and the microvessels were photographed under fluorescence microscope (DM6000; Leica). MVD was assessed by calculating the number of microvessels per square millimeter (vessel number $/ \mathrm{mm}^{2}$ ).

\section{Statistical analysis}

Data were expressed as mean \pm standard error of the mean or mean \pm SD. The data were analyzed by SPSS 20.0 software (IBM Corporation, Armonk, NY, USA) using one-way analysis of variance. The effects of time and treatments for paired comparisons were evaluated by Bonferroni's test. The $p$-values below 0.05 indicated statistical significance.

\section{Results and discussion}

In this study, we performed a series of experiments to investigate the properties of the $\mathrm{MG}$ and the efficacy of its combination with SCs under MF exposure on improving axonal regeneration and functional recovery after a $15 \mathrm{~mm}$ sciatic nerve defect was made. Figure 1A shows the experimental time scale, and Figure 1B shows that the MG combined with SCs was transplanted to bridge the $15 \mathrm{~mm}$ sciatic nerve gap in rats under the microscope, and a high purity of SCs $(>97 \%)$ is shown in Figure $1 \mathrm{C}-\mathrm{F}$. Figure $1 \mathrm{G}$ illustrates the schematic diagram of the major process of this study. Based on the in vivo experiments, the combination of the SCs-loaded MGs and MF exposure promoted nerve regeneration in rats.

In recent decades, MNPs have attracted increasing interest for use in biomedical applications, such as in the fields of magnetic resonance imaging, drug delivery, and cancer therapy. ${ }^{31-34}$ In this study, the MNPs were synthesized and the morphology was determined by TEM (Figure 2A). Figure 2B shows that MNPs were fairly uniform in distribution and the average particle diameter was $28.90 \pm 9.34 \mathrm{~nm}$. Figure 2C reveals that the crystalline characteristic of MNPs tested by 
A
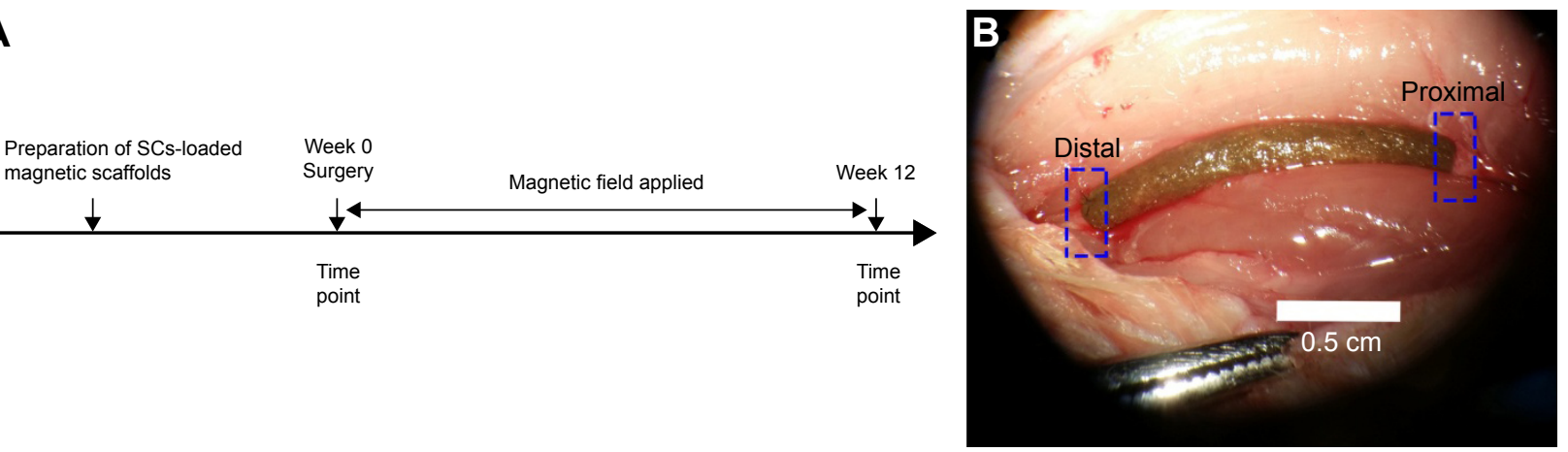

\section{S-100}

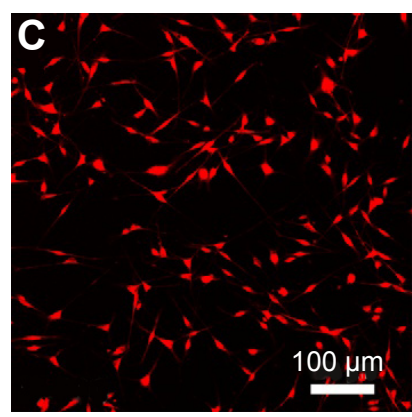

sox-10

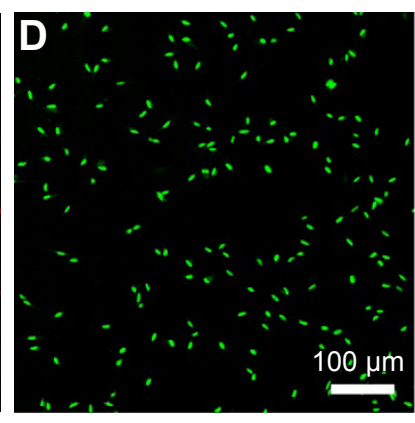

DAPI

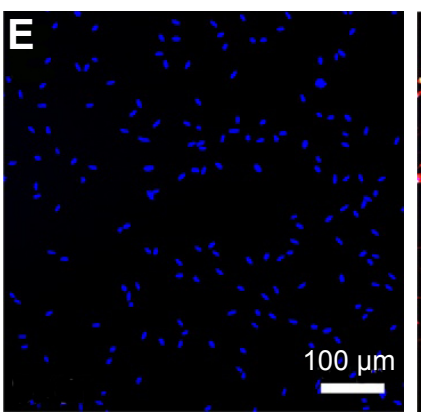

Merge

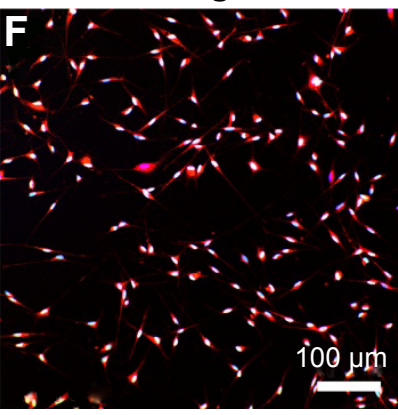

G

Magnetic nanoparticle
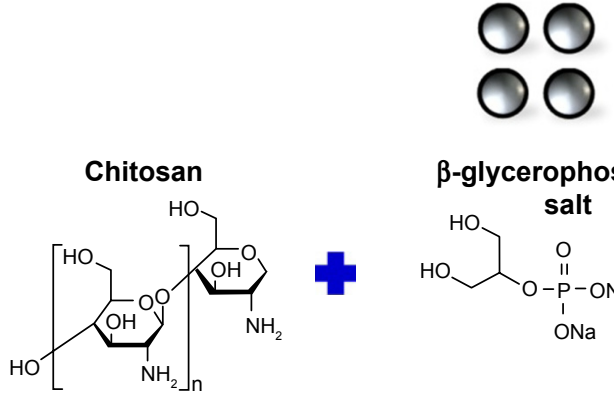

\section{$\beta$-glycerophosphate}
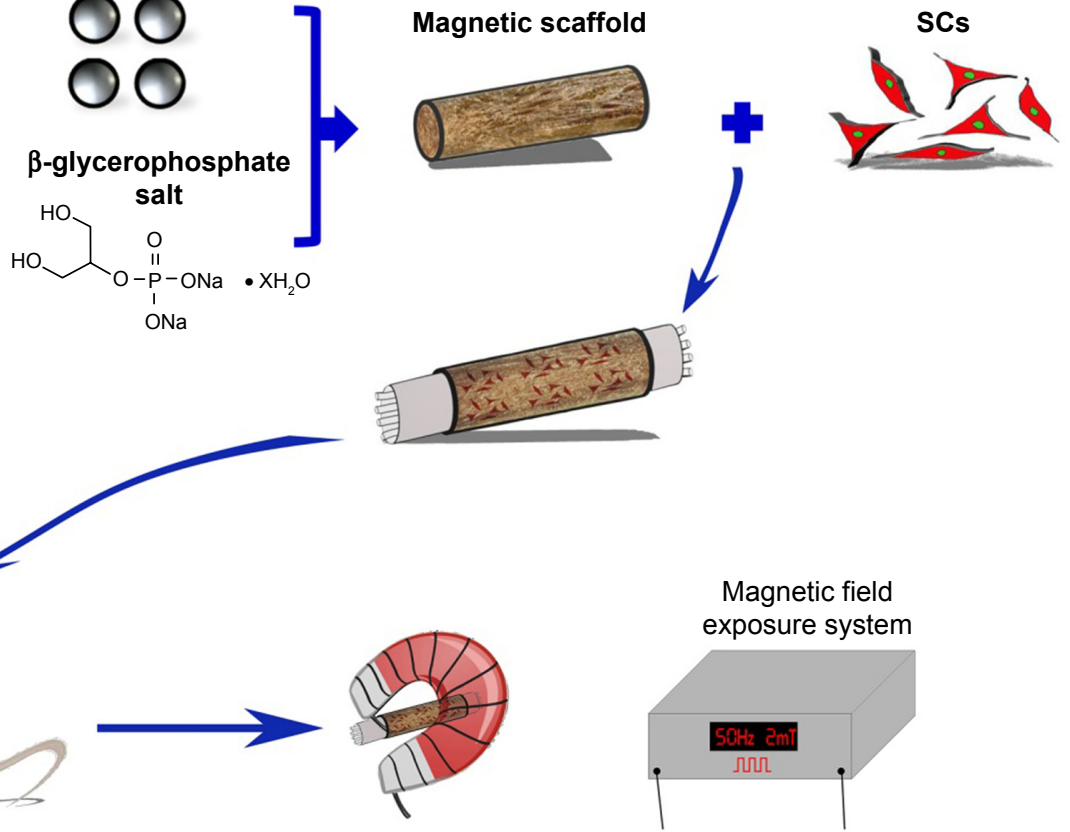

Figure I Schematic of this study.

Notes: (A) Time scale. (B) The SCs-loaded magnetic scaffold bridging $15 \mathrm{~mm}$ sciatic nerve defect in rats under the microscope. (C-E) Double immunofluorescent staining shows positive S-100 and SOX-10 with DAPI nuclear counterstaining. (F) Merged image shows a high purity of SCs (>97\%). (G) The schematic diagram of the main process of the experiment.

Abbreviations: DAPI, 4',6-diamidino-2-phenylindole; SCs, Schwann cells.

X-ray diffraction was nearly in conformity to the standard crystal structure of iron oxide. ${ }^{35}$ Meanwhile, magnetization of MNPs revealed superparamagnetism (Figure 2D).

Nevertheless, MNPs alone may be unable to provide optimal properties. Integration of MNPs with other desirable components is a promising approach to fabricate nanocomposites with integrated properties for biomedical applications. ${ }^{21}$ In this study, we integrated MNPs into a chitosan-glycerophosphate mixture, which are biodegradable, nontoxic, and mucoadhesive polymers and showed 

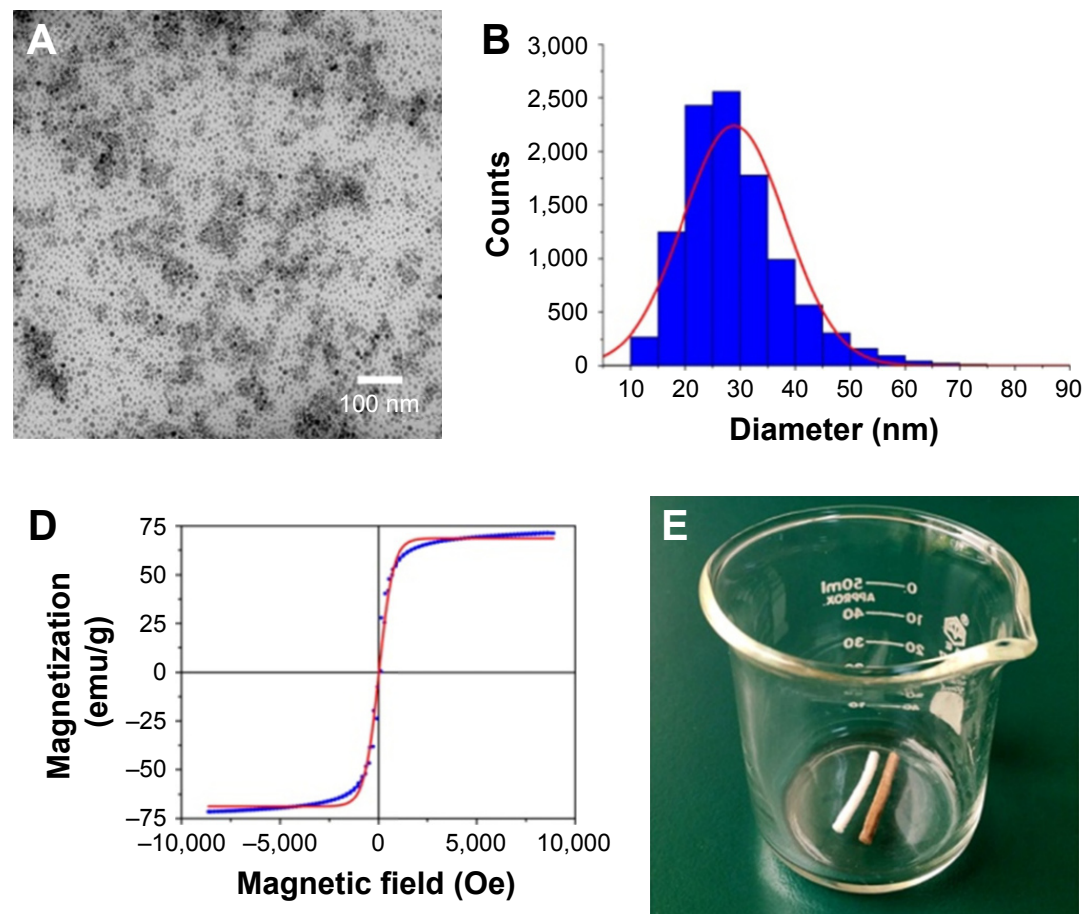
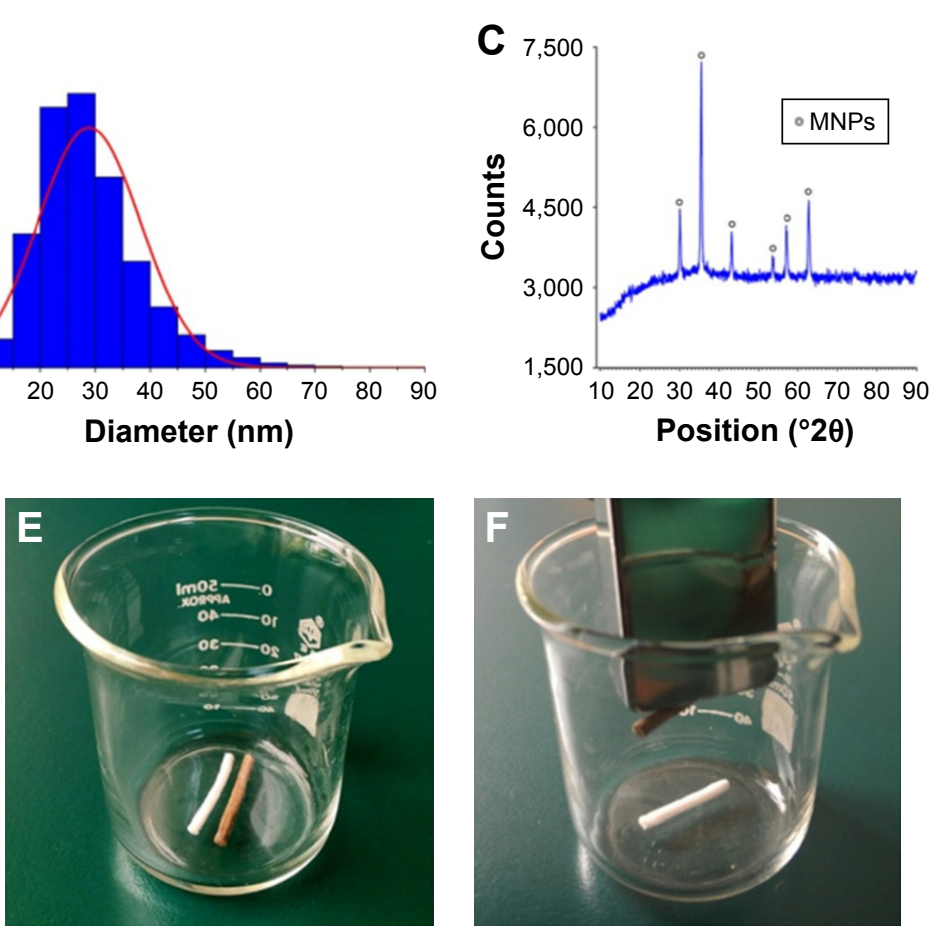
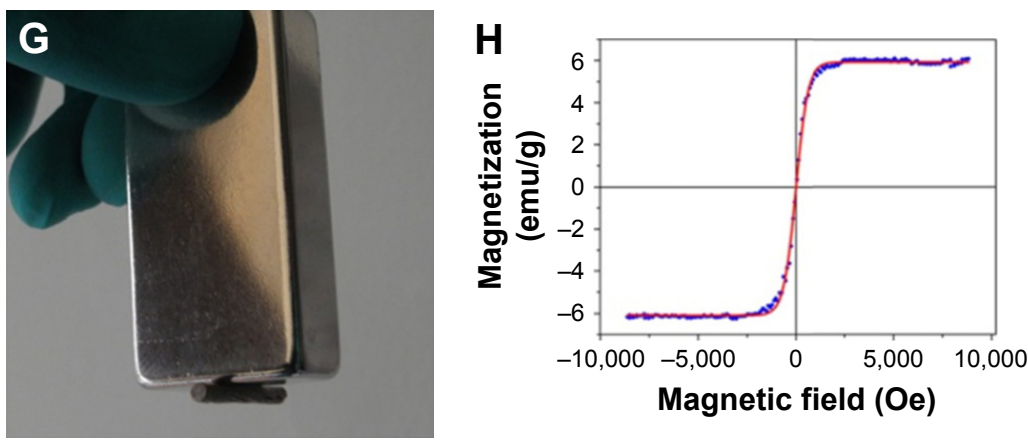

Figure 2 The features of MNPs and the general view and magnetization of the magnetic scaffold.

Notes: (A) TEM of MNPs. (B) Size distribution of MNPs. (C) XRD. (D) Magnetization of MNPs. (E) The view of nonmagnetic scaffold and magnetic scaffold. (F and G) Pictures exhibiting the magnetic attraction under a magnet. $(\mathbf{H})$ The magnetization of the magnetic scaffold was performed by VSM.

Abbreviations: MNPs, magnetic nanoparticles; TEM, transmission electron microscopy; XRD, X-ray diffraction; VSM, vibrating sample magnetometer.

good biocompatibility for neuron survival, ${ }^{36}$ to form a magnetic nanocomposite scaffold. Figure $2 \mathrm{E}$ shows the fabricated MG. The magnetic property was determined using a magnet (Figure $2 \mathrm{~F}$ and $\mathrm{G}$ ). Figure $2 \mathrm{H}$ shows that the MG had superparamagnetism at room temperature. In addition, the $\mathrm{M}_{\mathrm{L}}$, which stands for the magnetization measure at low MF of $34 \mathrm{Oe}$, was $0.189 \mathrm{emu} / \mathrm{g}$, and the $\mathrm{M}_{\mathrm{H}}$, which stands for the magnetization at high MF of $8 \mathrm{kOe}$, was $5.722 \mathrm{emu} / \mathrm{g}$, indicating that the MG may work as a topical MF inductor and its inherent magnetization could be inspired by MF, and the MG might be capable of being motivated continuously by the external MF because of the ingredient of MNPs.

The styles of the scaffolds used in the peripheral nerve regeneration were diverse, such as one tube, multitubes, cylinder, and so on, and the applications and effects of the above-mentioned scaffolds in promoting nerve regeneration also had their advantages and disadvantages ${ }^{5,37-39} \mathrm{Cyl}-$ inder scaffold, with its inner microchannels being made to imitate the basal nerve structures and allow the regenerating neurite outgrowth, ${ }^{5}$ was applied in our experiments. In brief, we fabricated the non-MGs and MGs using a tailored module (Figure 3A). On comparing with the white and transparent color of the non-MG (Figure $3 \mathrm{G}$ and $\mathrm{H}$ ), the color of the magnetic scaffold was uniformly chocolate (Figure 3B and C), showing that the MNPs were homogeneously distributed in the material. In addition, Figure $3 \mathrm{D}$ and I shows that the general structure of the non-MGs and MGs was relatively porous under scanning electron microscope in the transverse view, and the non-MGs and 

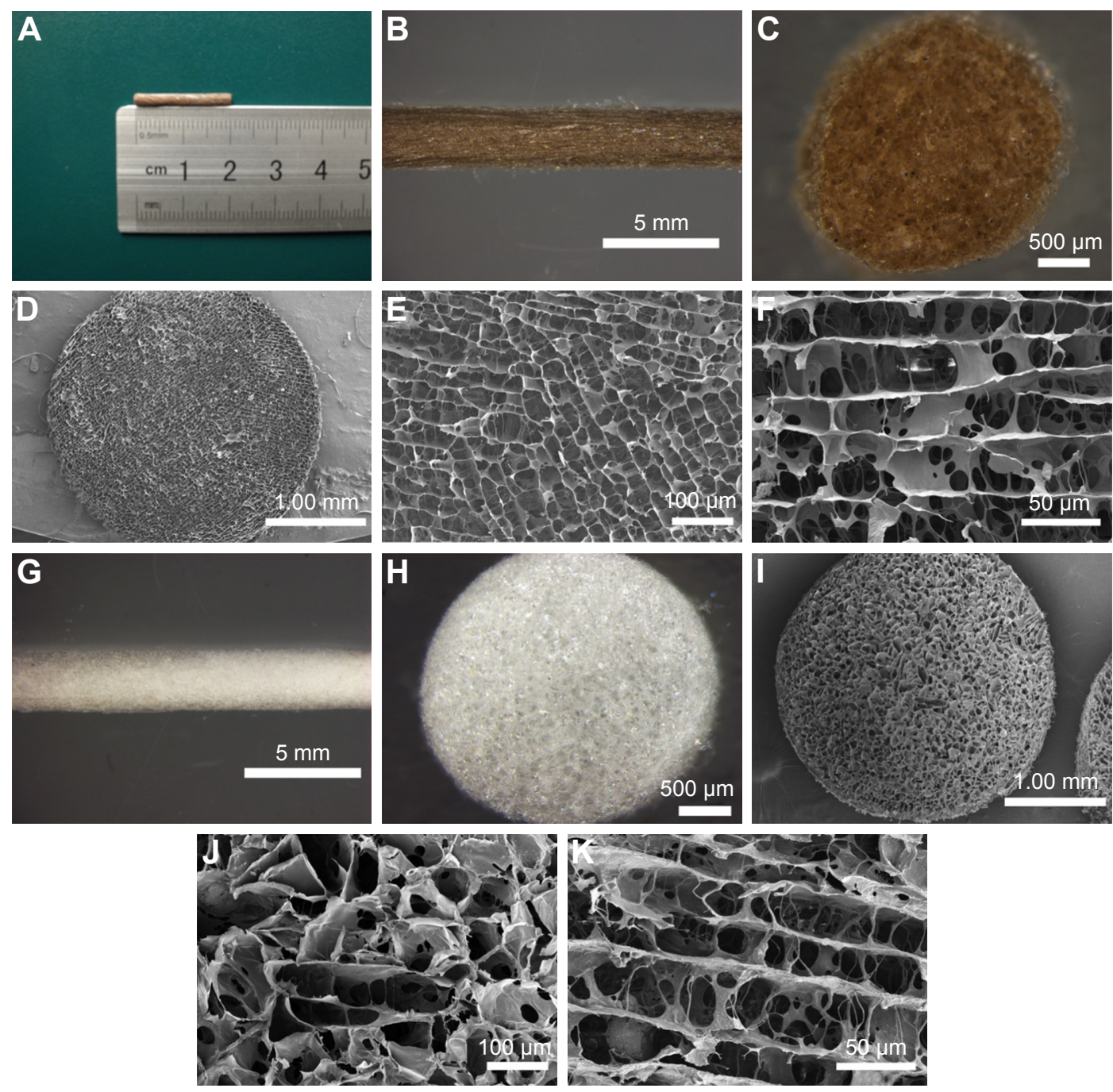

Figure 3 The morphology of the nonmagnetic and magnetic scaffolds.

Notes: (A) The length of the magnetic scaffold. (B, C, G, and $\mathbf{H}$ ) The general and cross-sectional appearance of the magnetic and nonmagnetic scaffolds under stereomicroscope, respectively. (D and I) The general structures of the magnetic and nonmagnetic scaffolds under SEM, respectively. (E and J) Representative transverse photographs of the magnetic and nonmagnetic scaffolds, showing that the microarrays were formed in a honeycomb-shaped characteristic. (F and $\mathbf{K})$ Representative longitudinal photographs of the magnetic and nonmagnetic scaffolds, displaying the interconnected cellular architecture and lengthwise oriented microchannels.

Abbreviation: SEM, scanning electron microscopy.

MGs displayed a honeycomb-shaped characteristic in the cross section (Figure 3E and $\mathrm{J}$ ) and longitudinally oriented microarrays with various lengths in the lengthwise section (Figure $3 \mathrm{~F}$ and $\mathrm{K}$ ). The mean diameter of the magnetic scaffold in cross section was $31.03 \pm 1.71 \mu \mathrm{m}$, which was $\sim 30 \mu \mathrm{m}$, and this was most valid for enhancing oriented neurite outgrowth, ${ }^{40}$ since it is suitable for the alignment and guiding of the regenerating axons, as well as for the infiltration of cells and vascularization that facilitates regeneration. ${ }^{41,42}$ However, the mean diameter of the nonMGs in the cross section was $37.56 \pm 1.90 \mu \mathrm{m}$, which was significantly larger than the MG, and this might be that the nanosized MNPs put a cross-linking role in the integration into the chitosan-glycerophosphate mixture. ${ }^{43}$ The cross-linking function of nanosized MNPs in the MG was achieved by decreasing the biopolymer-chain distance, thus leading to the potentialities of less inner-space interconnection and more sealed microchannels. Moreover, the size of MNPs was varied, and the different diameters of MNPs might play a diverse role in the fabricated magnetic nanocomposites and then affect the interaction between the magnetic nanocomposites and cells. Further studies are needed to determine its effects.

The degradation time of materials is a crucial requirement to the application of all tissue engineering medical products, and the appropriate degradation rate allowed the nerve implant to afford a stable architecture for supporting the neonatally regenerating nerve during the first $4-6$ months. ${ }^{23}$ 
A

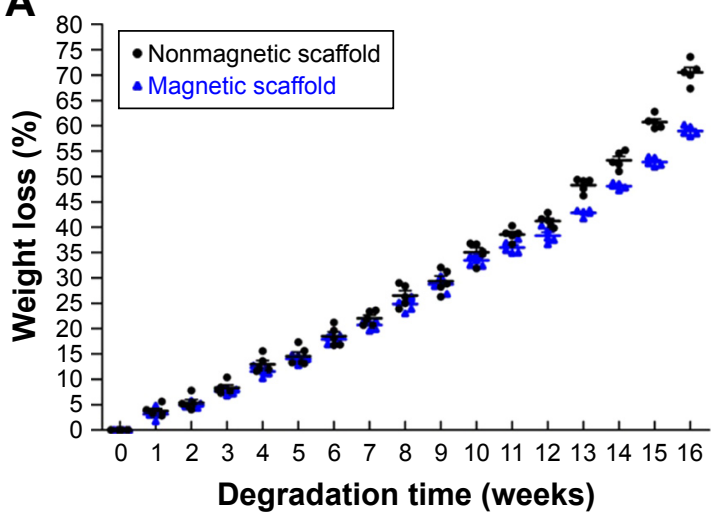

B

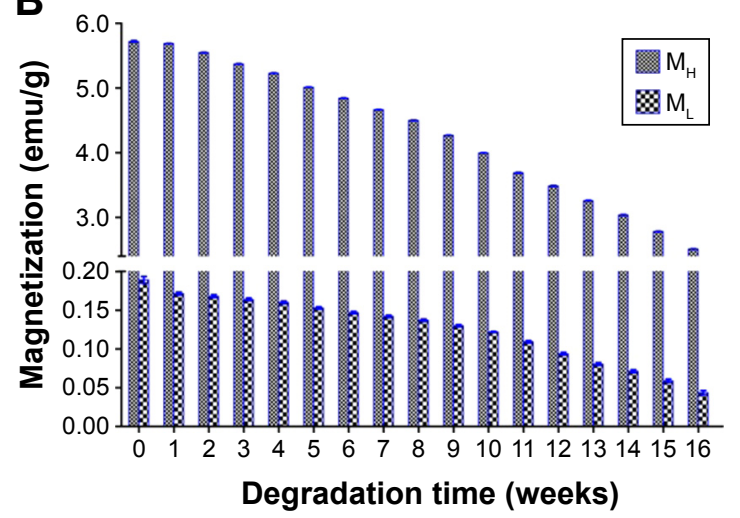

Figure 4 The weight loss and the magnetization variations during the degradation time.

Notes: (A) The weight loss of the nonmagnetic scaffold and magnetic scaffold during 16 weeks. (B) The $M_{H}$ and $M_{L}$ variations of the magnetic scaffold in the process of weight loss during 16 weeks.

Abbreviations: MF, magnetic field; $M_{H}$, the magnetization at high MF of $8 \mathrm{kOe}$; $M_{\mathrm{L}}$, the magnetization measure at low MF of 34 Oe.

In this study, the degradation test indicated that the MG was biodegradable, and the weight loss was $38.31 \% \pm 0.67 \%$ after 12 weeks and $58.96 \% \pm 0.43 \%$ after 16 weeks (Figure $4 \mathrm{~A}$ ), indicating that the MG was capable of supporting the regenerating axons. Figure 4B shows that after 12 weeks, the $M_{L}$ was $0.094 \mathrm{emu} / \mathrm{g}$ and the $\mathrm{M}_{\mathrm{H}}$ was $3.487 \mathrm{emu} / \mathrm{g}$, and after 16 weeks, the $M_{L}$ was $0.044 \mathrm{emu} / \mathrm{g}$ and the $M_{H}$ was $2.512 \mathrm{emu} / \mathrm{g}$, suggesting that the $\mathrm{MG}$ can be well responsive during the MF exposure period after bridging the sciatic nerve gap.

Biodegradation and biocompatibility of neural engineering materials in vivo are two important parameters for their application in peripheral nerve repair. ${ }^{44}$ Therefore, the in vivo tissue response of the sciatic nerve and the ambient tissues to implants was determined. Figure $5 \mathrm{~A}$ and $\mathrm{C}$ shows that acute inflammation and fibrous capsule formation were
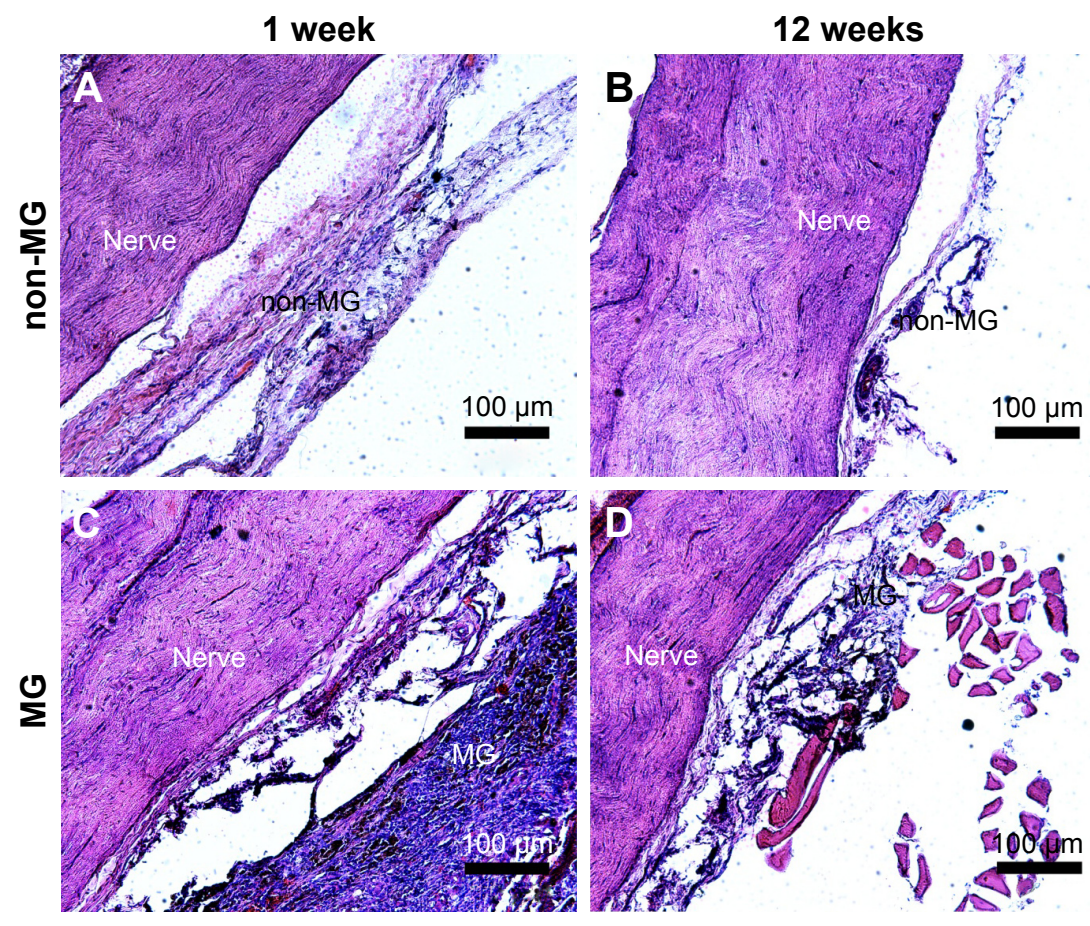

Figure 5 In vivo response of the nerve to the magnetic scaffold.

Notes: (A) The representative images of the area surrounding both the sciatic nerve and the non-MG at I week postoperation. (B) The representative images of the area surrounding both the sciatic nerve and the non-MG at 12 weeks postoperation. (C) The representative images of the area surrounding both the sciatic nerve and the MG at I week postoperation. (D) The representative images of the area surrounding both the sciatic nerve and the MG at I2 weeks postoperation. Abbreviations: MG, magnetic scaffold; non-MG, nonmagnetic scaffold. 
observed at 1 week after surgery in the area of both scaffolds. The acute inflammation of the MG was visible by the presence of the surrounding macrophages and fibrous tissue. Figure $5 \mathrm{~B}$ and $\mathrm{D}$ shows that both scaffolds were degraded and the fibrous capsule thickness of the scaffolds was reduced, indicating the chronic inflammatory response of both scaffolds. Moreover, the observation of the nerve was not affected by either the non-MG or the MG at 1 and 12 weeks postoperation. These findings suggest that the magnetic scaffolds we fabricated were biodegradable and biocompatible for their further application in bridging the sciatic nerve gap in vivo. In addition, along with the degradable process of the MG, the MNPs in the scaffold were released back into the surrounding environment. Much work has shown that the size of MNPs determined their half-life in the circulation. ${ }^{45}$ For instance, MNPs with sizes larger than $200 \mathrm{~nm}$ became concentrated in the spleen or were ingested by phagocytes of the body, whereas MNPs smaller than $10 \mathrm{~nm}$ were largely removed by renal clearance. When the size of MNPs was in the range of 10-100 $\mathrm{nm}$, they were able to penetrate through small capillaries ${ }^{46}$ and then to be carried through the blood circulation into the heart, lung, liver, or kidney. A previous study had shown that the MNPs (average diameter of $18 \mathrm{~nm}$ ) integrated into MG had no indications of any pathologic changes in the heart, lung, liver, spleen, and kidney during the experiment, indicating that the recirculated MNPs had no harmful influence on the organ functions of the animal. ${ }^{20}$ In our study, the average size of MNPs was $28.90 \pm 9.34 \mathrm{~nm}$, which may also be recirculated into the blood vessel during the degradable process and then be flown into the visceral organs. Further studies are needed to evaluate the distribution of recirculated MNPs in the organs, in order to shed light on the effect of the degradable ingredients on rats.

An adequate cell seeding efficiency and cell distribution are the two key factors to consider currently when combining nerve materials with supportive cells for nerve repair. ${ }^{47}$ Therefore, we injected the SCs into the magnetically responsive scaffold for a higher seeding efficiency and homogeneous distribution. Cell distribution within the nerve scaffolds was analyzed, and a large number of live SCs were uniformly distributed in the MG (Figure 6B, D, E, and G). The results supported the hypothesis that this MG, as a seeding cell carrier, was capable of increasing the seeding efficacy and allowing a homogenous cell distribution. In addition, cell viability within the MG was analyzed after surgery. Figure 6I shows that the number of live SCs, in comparison with the group without MF exposure, was significantly increased in the $\mathrm{MG}+\mathrm{SC}+\mathrm{MF}$ group at 3, 7, and 14 days after implantation. A previous in vitro study showed that a magnetic gel composed of MNPs, type II collagen, polyethylene glycol, and hyaluronic acid enhances the viability of bone marrow-derived mesenchymal stem cells, ${ }^{48}$ consistent with the findings of this study. Thus, the combination of the MG and MF exposure was capable of enhancing the survival of SCs in the early stage of implantation, which could be an important favorable factor for nerve regeneration after implantation.

The formation of regenerated axons was examined using toluidine blue staining to assess the effect of the combination of SCs-loaded MG and MF on axonal regeneration. Regenerating axons were observed at the distal ends in all groups at 4, 8, and 12 weeks postoperation (Figure 7A-E). However, massive axons, including myelinated axons and unmyelinated axons, were only observed in the MG+SCs+MF group and autograft group (Figure 7F and $\mathrm{J}$ ). In the $\mathrm{MG}+\mathrm{MF}$ and $\mathrm{MG}+\mathrm{SCs}$ groups, the regenerated axons showed an inferior morphologic appearance compared to the axons in the $\mathrm{MG}+\mathrm{SCs}+\mathrm{MF}$ group (Figure $7 \mathrm{H}$ and I), but had a better appearance than the axons in the MG group (Figure 7G). In addition, the total area of the regenerated axons (Figure 7P), the total number and the mean diameter of the myelinated axons (Figure 7Q and R) were similar between the autograft group and the $\mathrm{MG}+\mathrm{SCs}+\mathrm{MF}$ group, but were significantly increased compared to those in the other groups $(p<0.05$; Figure $7 \mathrm{P}-\mathrm{R})$. Moreover, the G-ratio measurement indicated that the degree of myelination was significantly improved in the $\mathrm{MG}+\mathrm{SCs}+\mathrm{MF}$ group compared to that in other groups $(p<0.05$; Figure $7 \mathrm{~S})$. In addition, no statistical significance was observed in the parameters described earlier between the autograft group and the MG+SCs+MF group ( $p>0.05$; Figure $7 \mathrm{~S}$ ). These findings indicated that the amount of myelinated axons in nerve grafts was comparable between the autograft group and the $\mathrm{MG}+\mathrm{SCs}+\mathrm{MF}$ group at 12 weeks postoperation, which was significantly increased compared to that in other groups. Meanwhile, the myelinated axons were evenly distributed in the MG+SCs+MF group.

Furthermore, double S-100/NF200 immunofluorescence staining in all sections of the regenerated nerve also revealed that the migrated SCs and regenerated axons were evenly distributed in the autograft group and $\mathrm{MG}+\mathrm{SCs}+\mathrm{MF}$ group (Figure 8A-D and Q-T) 12 weeks after the operation and revealed a better morphologic appearance than the axons in the $\mathrm{MG}, \mathrm{MG}+\mathrm{MF}$, and $\mathrm{MG}+\mathrm{SC}$ groups (Figure 8E-P). 

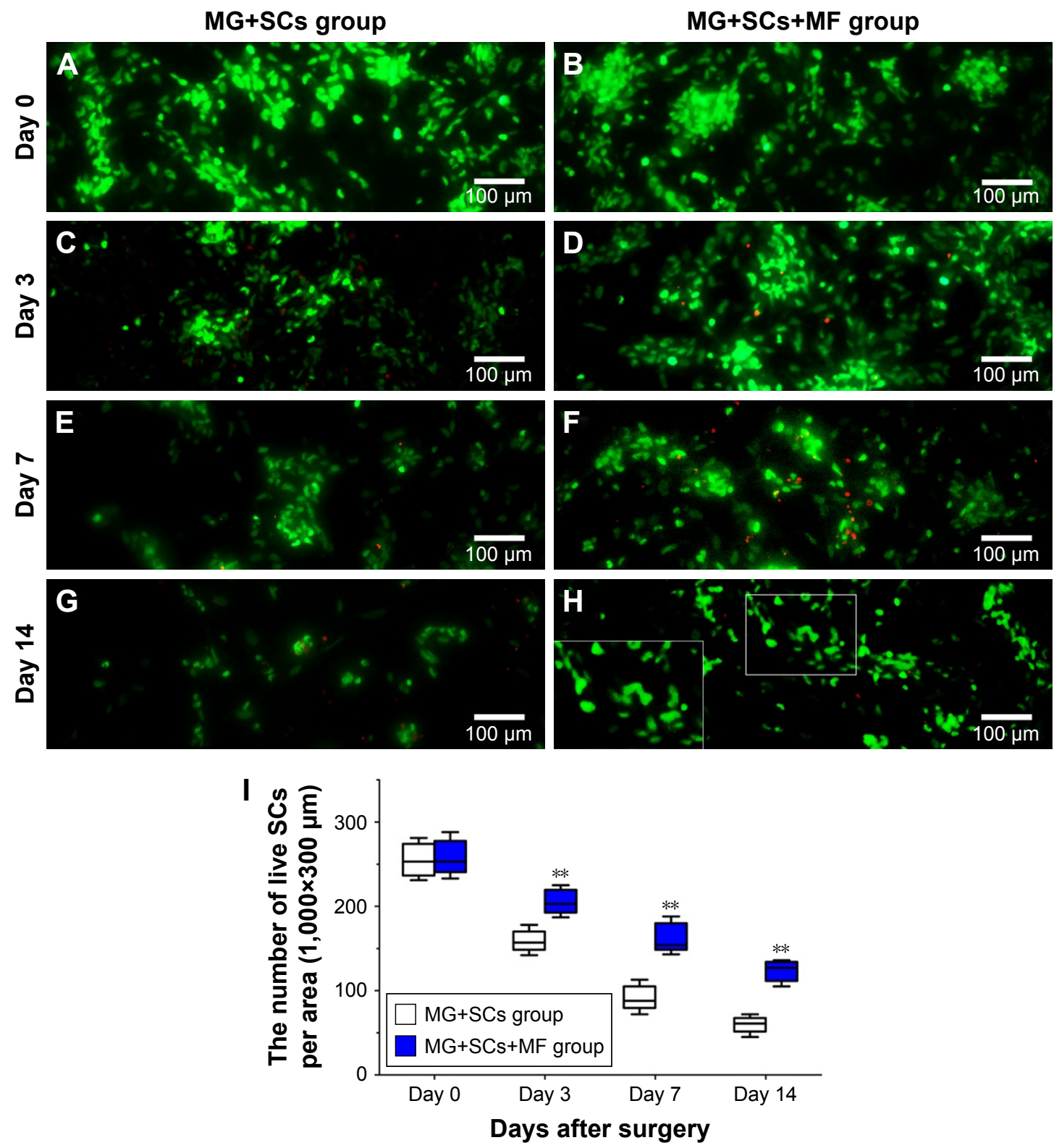

Figure 6 Effect of SCs' viability in magnetic scaffold in vivo.

Notes: (A, C, E, and G) Live/dead staining of SCs on day 0, 3, 7, and 14 in MG+SCs group postoperation, respectively. (B, D, F, and H) Live/dead staining of SCs on day 0 , 3, 7, and I4 in MG+SCs+MF group postoperation, respectively. (I) Quantification of live SCs from images on day $0,3,7$, and I4. **p $<0.01$; all results are expressed as the mean \pm SD.

Abbreviations: MG+SCs, the rats were bridged with the Schwann cells-loaded magnetic scaffold; MG+SCs+MF, the rats were bridged with the Schwann cells-loaded magnetic scaffold and under MF after surgery; MF, magnetic field; SCs, Schwann cells.

According to the SFI measurements shown in Figure 9A, motor function recovery was achieved in all groups at 4,8 , and 12 weeks postoperation. However, better motor functional recovery was shown by the MG+SCs+MF group, with higher SFI values than the rats in the MG, MG+MF, and $\mathrm{MG}+\mathrm{SCs}$ groups $(p<0.05$; Figure 9B). Figure $9 \mathrm{C}$ indicates that sensory functional recovery was achieved in all groups at the predefined time postoperation, according to the thermal hind paw withdrawal test. The rats in the MG+SCs+MF group exhibited better sensory functional recovery, with quicker response to thermal stimulus than the rats in other groups $(p<0.05$; Figure 9C). Moreover, the SFI values and hind paw withdrawal latency time were similar in the autograft group and the $\mathrm{MG}+\mathrm{SCs}+\mathrm{MF}$ group at the predefined time ( $p>0.05$; Figure 9B and $C$ ), indicating that more axons might successfully regenerate through the magnetic scaffolds from the proximal stumps to the distal stumps and reinnervate the target muscles.

Retrograde FG staining of spinal motoneurons and DRG sensory neurons was performed to analyze the 

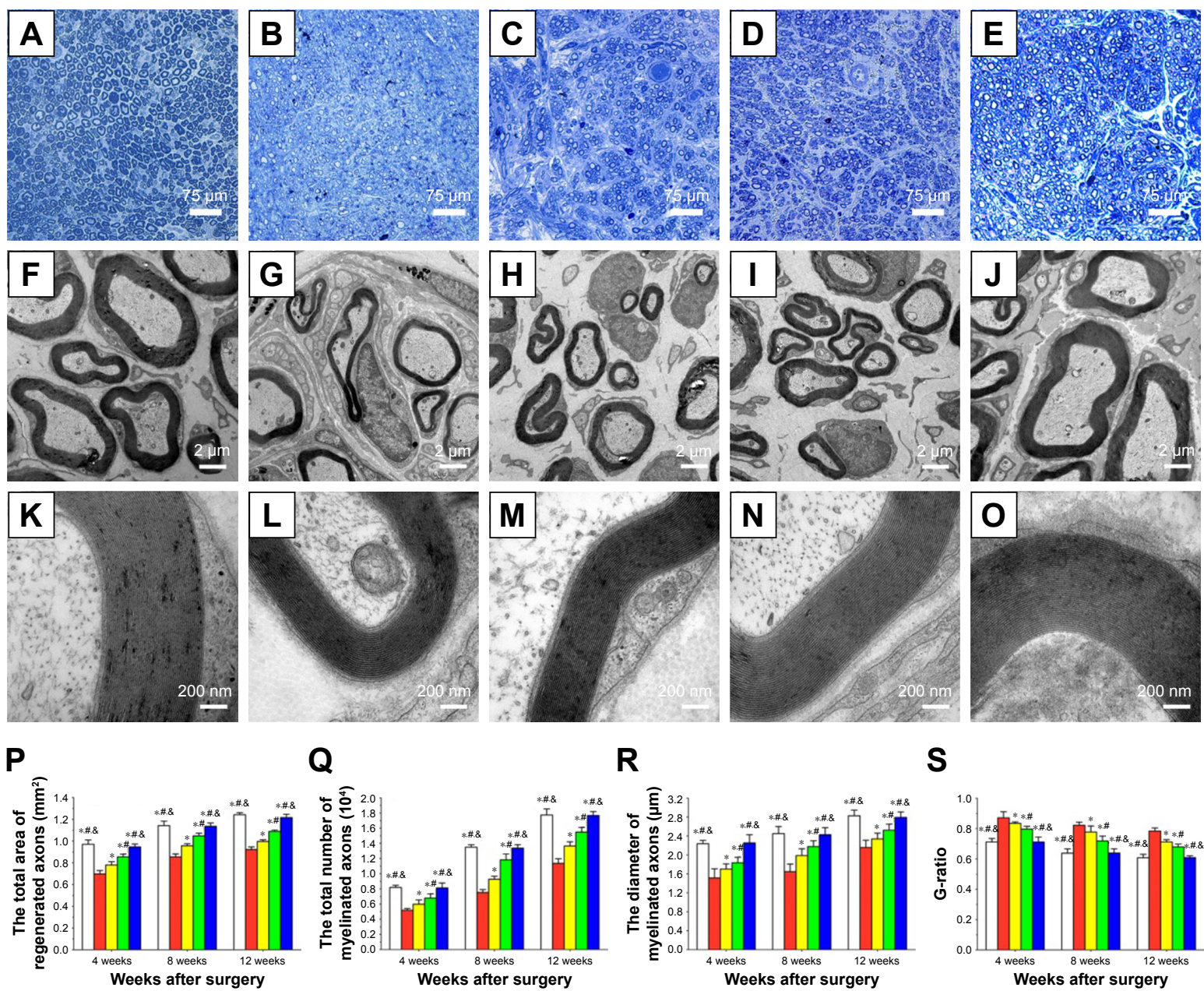

Q

$\mathbf{R}$

S
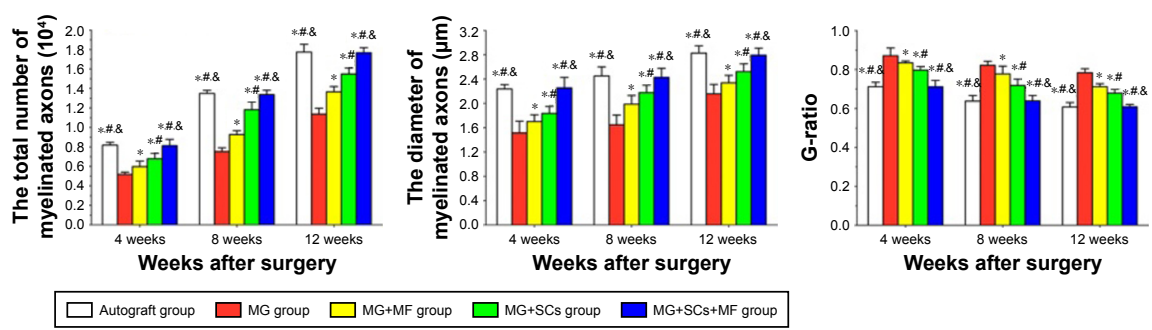

Figure 7 Morphologic appearance and morphometric assessments of regenerated nerves in each group.

Notes: (A-E) The characteristic toluidine blue photographs of regenerated axons in the autograft group, MG group, MG+MF group, MG+SCs group, and MG+SCs+MF group at 12 weeks postoperation, respectively. $(\mathbf{F}-\mathbf{O})$ The characteristic electron micrographs of regenerated axons in the middle part of the scaffold in the $(\mathbf{F})$ autograft group, (G) MG group, (H) MG+MF group, (I) MG+SCs group, and (J) MG+SCs+MF group at I2 weeks postoperation. (K-O) The characteristic electron micrographs of myelin sheath in the middle part of the scaffold in the autograft group, MG group, MG+MF group, MG+SCs group, and MG+SCs+MF group at 12 weeks postoperation. (P) The cross-sectional area of regenerated nerves in the scaffold. (Q) Quantitative analysis of myelinated axons in the scaffold. (R) The diameter of myelinated axons in the scaffold. (S) The G-ratios in the scaffold. ${ }^{p} p<0.05$ compared to MG group; ${ }^{*} p<0.05$ compared to MG+MF group; ${ }^{2} p<0.05$ compared to MG+SCs group; all results are expressed as the mean \pm standard error of mean.

Abbreviations: MG, the rats were bridged with the magnetic scaffold; MG+MF, the rats were bridged with the magnetic scaffold and under MF exposure after surgery; MG+SCs, the rats were bridged with the Schwann cells-loaded magnetic scaffold; MG+SCs+MF, the rats were bridged with the Schwann cells-loaded magnetic scaffold and under MF after surgery; MF, magnetic field; SCs, Schwann cells.

neurons whose axons successfully regenerated through the scaffolds. The numbers of FG-positive motoneurons and sensory neurons were similar in the autograft group and the $\mathrm{MG}+\mathrm{SCs}+\mathrm{MF}$ group, but were significantly higher than the numbers observed in other groups $(p<0.05$; Figure 10A, $\mathrm{E}, \mathrm{F}$, and $\mathrm{J}-\mathrm{L}$ ). Moreover, the number of FG-positive motoneurons and sensory neurons in the MG group was significantly decreased compared to the number observed in the $\mathrm{MG}+\mathrm{MF}$ and $\mathrm{MG}+\mathrm{SC}$ groups $(p<0.05$; Figure 10B-D, $\mathrm{G}-\mathrm{I}, \mathrm{K}$, and $\mathrm{L}$ ). Thus, these findings indicate that more nerve fibers from motoneurons and sensory neurons in the autograft group and $\mathrm{MG}+\mathrm{SC}+\mathrm{MF}$ group regenerated into the distal stumps than did the nerve fibers from the remaining groups.

Motor nerve injury results in atrophy of the denervated target muscle, which could be alleviated by reinnervation accompanied by a gradual functional recovery. Thus, weighting and morphologic assessments of the gastrocnemius muscles were performed to examine the effect of the combination of the SCs-loaded MG and MF exposure on motor function recovery. Figure 11A-E shows the representative photographs of the morphology of gastrocnemius 
A

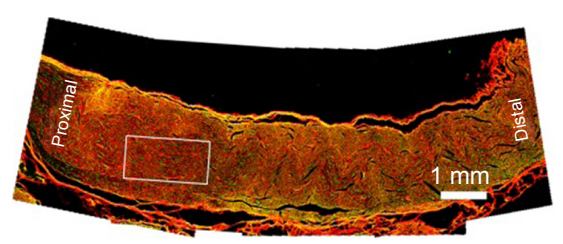

E

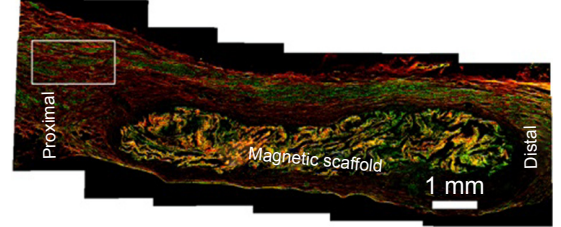

I

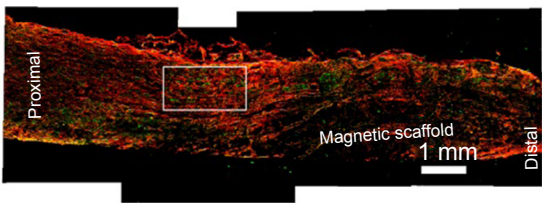

M

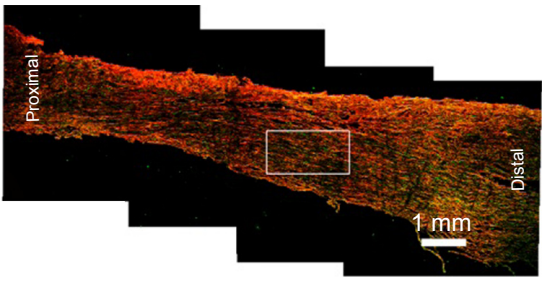

$\mathbf{Q}$

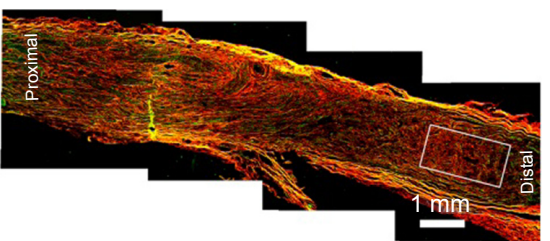

S-100
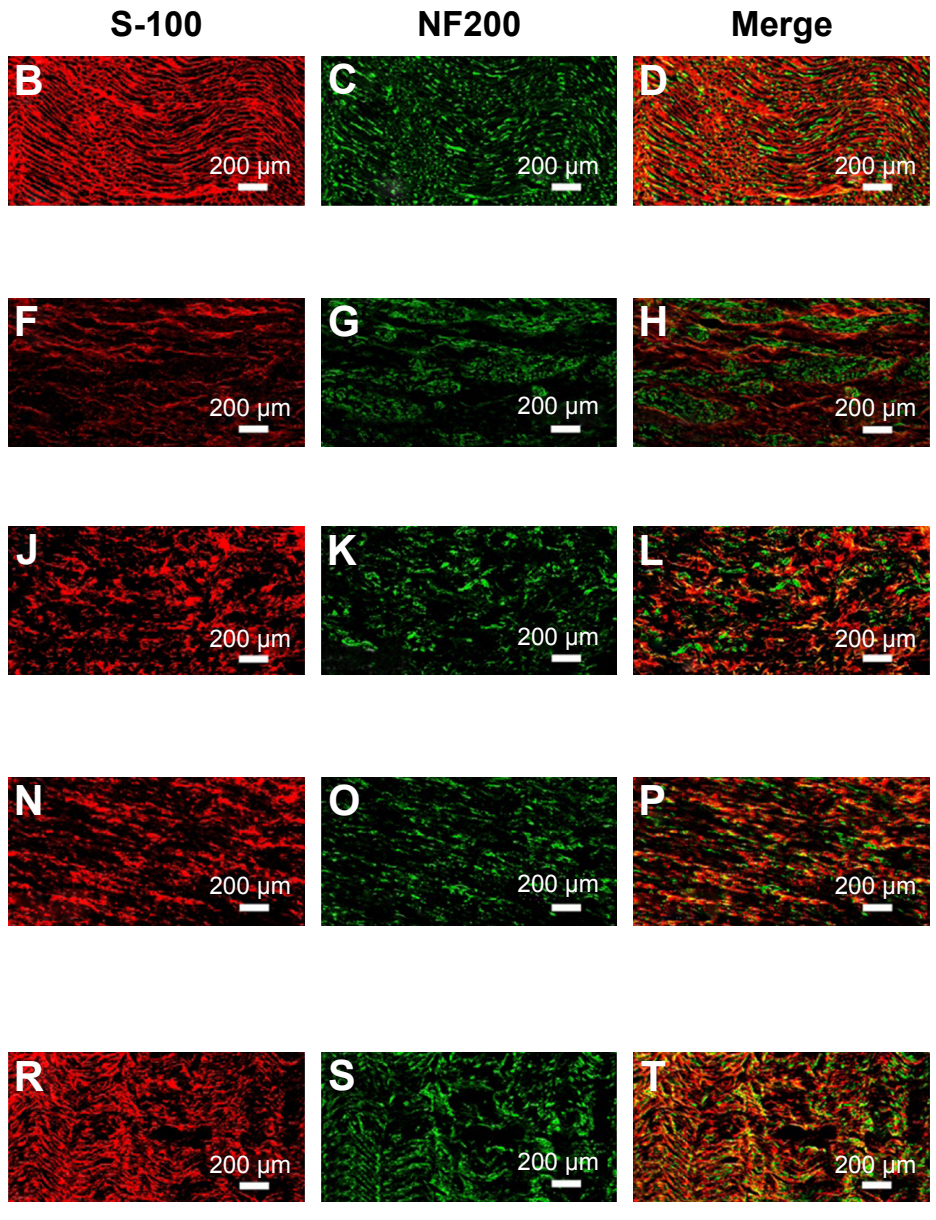

Figure 8 Double immunofluorescence assay for S-100 and NF200 in each group.

Notes: (A-D) Characteristic photographs of the regenerated nerves in the autograft group. (E-H) Characteristic photographs of the regenerated nerves in the MG group. (I-L) Characteristic photographs of the regenerated nerves in the MG+MF group. (M-P) Characteristic photographs of the regenerated nerves in the MG+SCs group. (Q-T) Characteristic photographs of the regenerated nerves in the MG+SCs+MF group.

Abbreviations: MG, the rats were bridged with the magnetic scaffold; MG+MF, the rats were bridged with the magnetic scaffold and under MF exposure after surgery; MG+SCs, the rats were bridged with the Schwann cells-loaded magnetic scaffold; MG+SCs+MF, the rats were bridged with the Schwann cells-loaded magnetic scaffold and under MF after surgery; MF, magnetic field; SCs, Schwann cells.

muscles in each group at 12 weeks postoperation. Also, Masson's trichrome staining in Figure $11 \mathrm{~F}-\mathrm{J}$ shows the percentage of muscle fiber area, and the average diameter of muscle fibers in the $\mathrm{MG}+\mathrm{MF}$ and $\mathrm{MG}+\mathrm{SCs}$ groups were significantly increased compared to the percentage in the MG group, indicating that the addition of SCs to MG or exposure to an MF partially prevented muscle atrophy. Moreover, the percentage area of muscle fiber and the average diameter of muscle fibers were similar in the autograft group and $\mathrm{MG}+\mathrm{SCs}+\mathrm{MF}$ group, but were significantly increased compared to the percentage in the $\mathrm{MG}, \mathrm{MG}+\mathrm{MF}$, and $\mathrm{MG}+\mathrm{SCs}$ groups at 12 weeks postoperation $(p<0.05$; Figure 11Q and R). Thus, a combination of SCs loaded in the magnetic scaffolds and MF exposure synergistically reversed muscle atrophy.

The viability and biologic functions of SCs which combined with scaffolds are relied upon both nutrient and oxygen utilization within the nerve scaffold. Vascularization is a critical factor for these purposes. Microvessels have been considered to play an efficient part in the delivery of nutrition and oxygen. Thus, an MVD experiment was performed to determine the effect of the combination of the SCs-loaded MG and MF exposure on microvessel growth within the nerve scaffold. As shown in the representative images, the MVD was comparable between the autograft group and the $\mathrm{MG}+\mathrm{SCs}+\mathrm{MF}$ group, but significantly increased compared to that in the other groups (Figure $11 \mathrm{~K}-\mathrm{O}$ ). Further quantitative analyses showed that the MVD in the MG+SCs group was increased compared to that in the MG group (Figure 11S), indicating that SCs increased the MVD in newly formed nerve tissues and promoted vascularization. In addition, the MVD in the MG+SCs+MF group was higher than the MVD without MF (Figure 11S), suggesting that following MF exposure, the SCs-loaded MG might enhance vascularization 
A
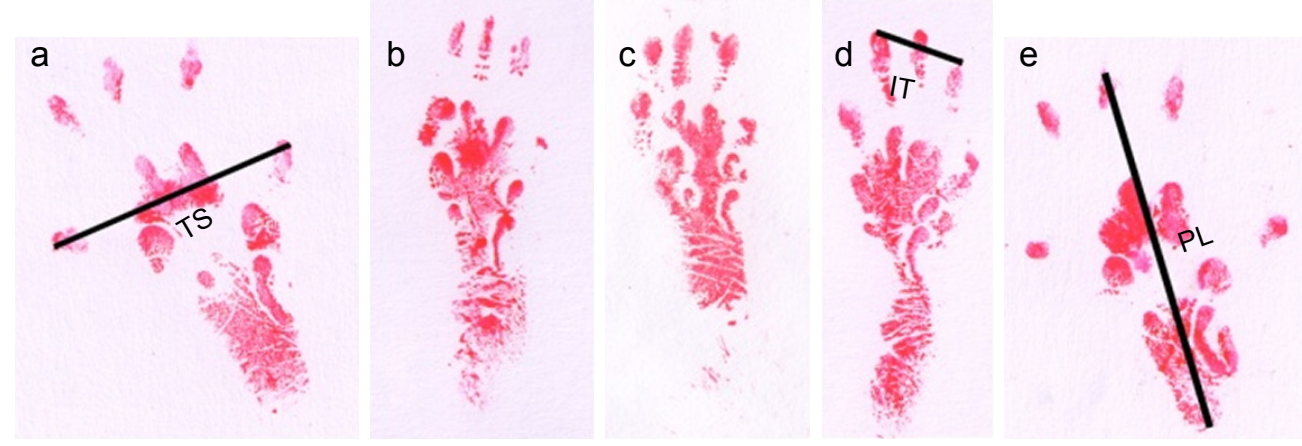

B

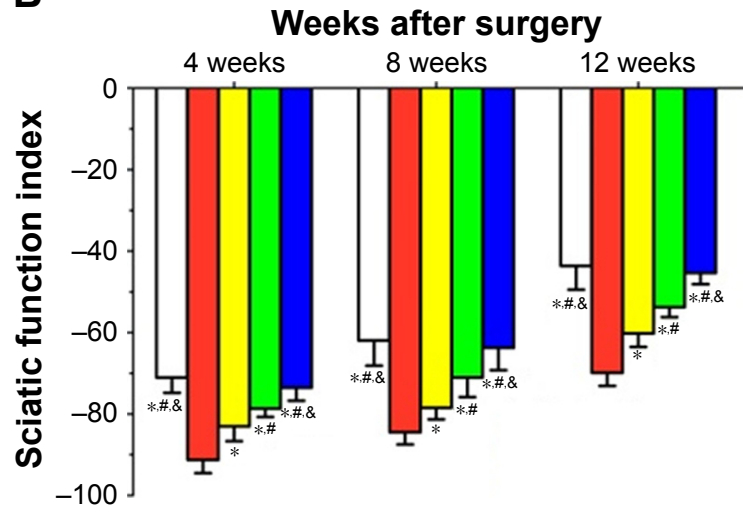

C

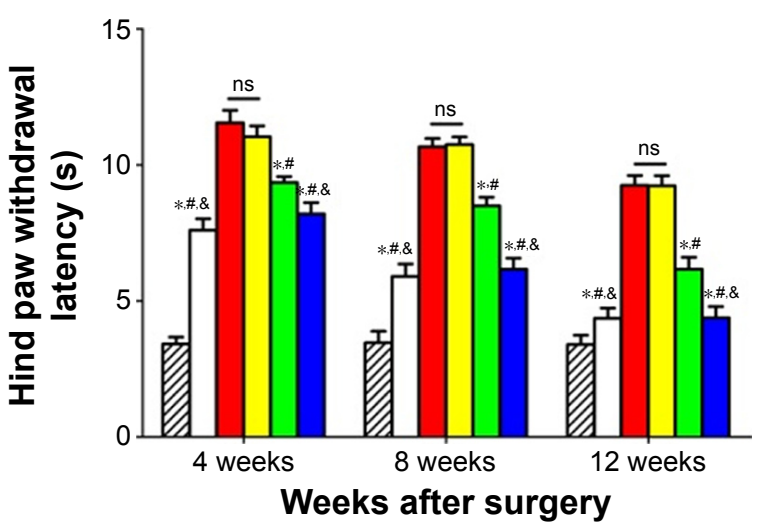

\begin{tabular}{|ll|}
\hline$\square$ Noninjured & $\square$ Autograft group \\
$\square$ MG group & $\square$ MG+MF group \\
$\square$ MG+SCs group & $\square$ MG+SCs+MF group \\
\hline
\end{tabular}

Figure 9 The sciatic functional index in each group.

Notes: (A) The operative left footprints at 12 weeks postoperatively; (a-e) autograft group, MG group, MG+MF group, MG+SCs group, and MG+SCs+MF group. (B) The statistical data of the sciatic functional index. (C) The hind paw withdrawal latency time. ${ }^{*} p<0.05$ compared to MG group; ${ }^{*}<<0.05$ compared to MG+MF group; ${ }^{2} p<0.05$ compared to MG+SCs group; all results are presented as the mean \pm standard eror of the mean.

Abbreviations: MG, the rats were bridged with the magnetic scaffold; MG+MF, the rats were bridged with the magnetic scaffold and under MF exposure after surgery; MG+SCs, the rats were bridged with the Schwann cells-loaded magnetic scaffold; MG+SCs+MF, the rats were bridged with the Schwann cells-loaded magnetic scaffold and under MF after surgery; ns, not significant; MF, magnetic field; SCs, Schwann cells; IT, intermediary toe spread (distance between the second and the fourth toe); PL, print length (distance between the heel and the top of the third toe); TS, toe spread (distance between the first and the fifth toe).

by promoting the survival of SCs and upregulating vascularization-related genes.

These findings, combined with the increased viability of SCs in the magnetic loading system under MF exposure after implantation, together reveal that SCs-loaded MG with MF exposure have beneficial effect on the axonal regeneration and neurologic functional recovery, which might be attributable to the synergistic effect of SCs-loaded
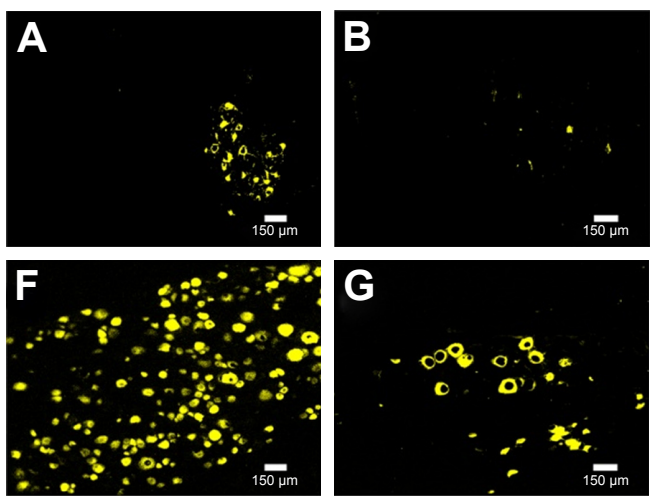
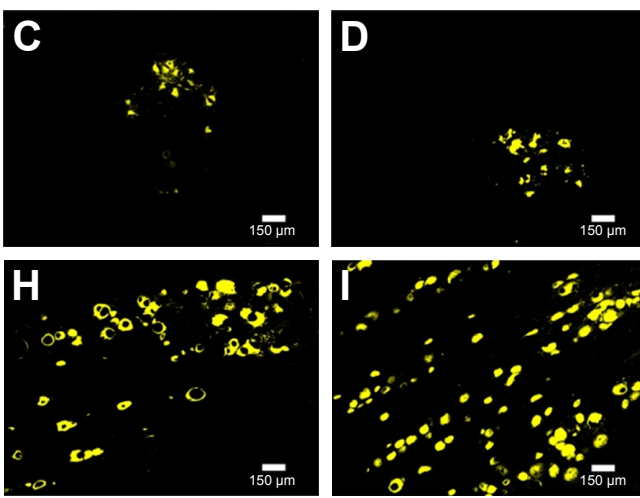
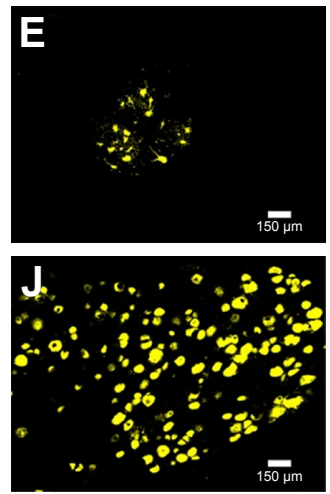

Figure 10 (Continued) 

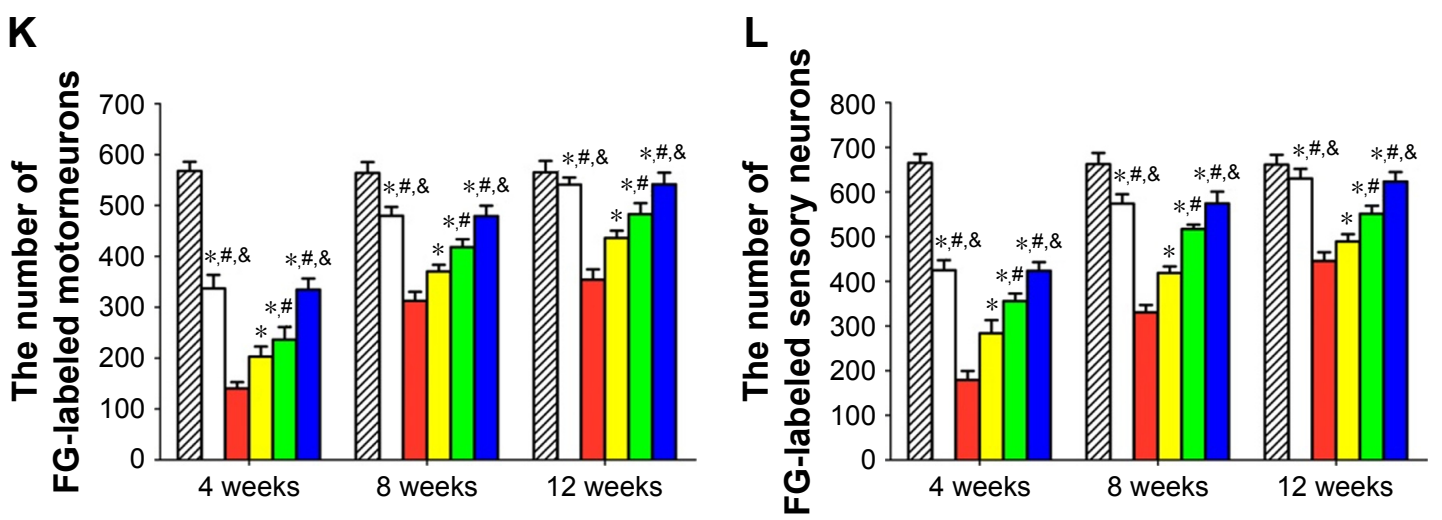

$$
\begin{array}{|ll|}
\square \text { Noninjured } & \square \text { Autograft group } \square \text { MG group } \square \text { MG+MF group } \\
\square \text { MG+SCs group } \quad \square \text { MG+SCs+MF group }
\end{array}
$$

Figure 10 Retrograde FG tracing in each group.

Notes: (A-E) FG-positive spinal motoneurons in autograft group, MG group, MG+MF group, MG+SCs group, and MG+SCs+MF group, respectively. (F-J) FG-positive DRG sensory neurons in autograft group, MG group, MG+MF group, MG+SCs group, and MG+SCs+MF group, respectively. (K and $\mathbf{L}$ ) The quantitative analysis of FG-positive motoneurons and sensory neurons in all groups, respectively. ${ }^{*} p<0.05$ compared to MG group; $p<0.05$ compared to MG+MF group; ${ }^{\circledR} p<0.05$ compared to MG+SCs group; all results are expressed as the mean \pm standard error of mean.

Abbreviations: FG, Fluoro-Gold; SCs, Schwann cells; MG, the rats were bridged with the magnetic scaffold; MG+MF, the rats were bridged with the magnetic scaffold and under MF exposure after surgery; MG+SCs, the rats were bridged with the Schwann cells-loaded magnetic scaffold; MG+SCs+MF, the rats were bridged with the Schwann cells-loaded magnetic scaffold and under MF after surgery; MF, magnetic field.
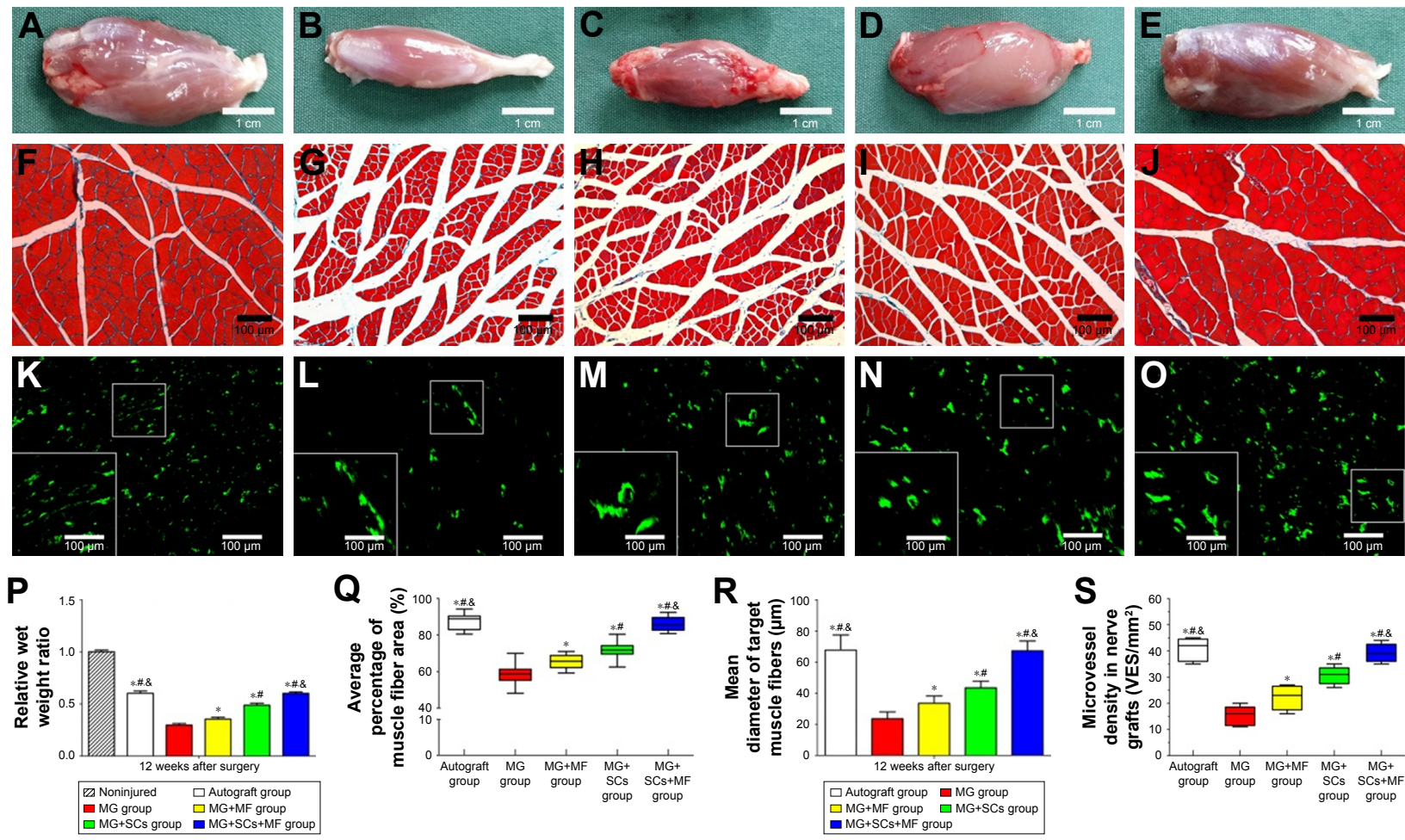

S

Figure I I Weighting and histology of target gastrocnemius muscle, and quantification of microvessel density (MVD) in each group.

Notes: (A-E) The morphology of the gastrocnemius muscle in the autograft group, MG group, MG+MF group, MG+SCs group, and MG+SCs+MF group at 12 weeks postoperation, respectively. (F-J) The characteristic light photographs of the cross-sectional gastrocnemius muscle following Masson trichrome staining (from left to right: the autograft group, MG group, MG+MF group, MG+SCs group, and MG+SCs+MF group) at I 2 weeks postoperation. (K-O) The characteristic photographs of MVD staining (from left to right: the autograft group, MG group, MG+MF group, MG+SCs group, and MG+SCs+MF group) at 12 weeks postoperation, respectively. (P) The relative wet weight ratio in each group is shown. (Q) The mean percentage area of muscle fibers in each group is shown. (R) The average diameter of muscle fibers in each group is shown. (S) The quantitative analysis of MVD in each group is shown. ${ }^{*} p<0.05$ compared to MG group; ${ }^{*} p<0.05$ compared to MG+MF group; ${ }^{\&} p<0.05$ compared to MG+SCs group; all results are expressed as the mean \pm SD.

Abbreviations: MG, the rats were bridged with the magnetic scaffold; MG+MF, the rats were bridged with the magnetic scaffold and under MF exposure after surgery; MG+SCs, the rats were bridged with the Schwann cells-loaded magnetic scaffold; MG+SCs+MF, the rats were bridged with the Schwann cells-loaded magnetic scaffold and under MF after surgery; SCs, Schwann cells; MF, magnetic field. 
MG and MF. Further studies will be needed to explore the intrinsic mechanism of the improving axon regeneration and neurological functional recovery after bridging the sciatic nerve defect using SCs-loaded MG in response to an applied MF.

\section{Conclusion}

A magnetically responsive nanocomposite scaffold was fabricated in this study from a mixture of MNPs and chitosanglycerophosphate polymers. The magnetic scaffolds have modest magnetization, proper degradation rate, and possess a tunable microstructure, making them suitable for cellular distribution and new axon regeneration. The combination of the magnetically responsive scaffold and SCs exposed to an MF synergistically improves nerve regeneration and functional recovery in vivo by increasing the distribution efficiency and viability of SCs. Our study reports a promising scaffold for nerve tissue engineering because the SC-loaded magnetic nanocomposite scaffold responded to an applied external MF, which may be used to remotely orient the scaffold to the nerve defect site using an externally applied MF.

\section{Acknowledgments}

This work was supported by grants from the National Natural Science Foundation of China $(81672148,81201389$, and 81501047), the National Basic Research Program of China (973 Program No 2014CB542206), the National Key Research and Development Plan (2016YFC1101700), the Program for Changjiang Scholar and Innovative Research Team in University (IRT1053 and IRT13051), and A Foundation for the Author of National Excellent Doctoral Dissertation of PR China (201480). We thank the following technicians for providing excellent technical assistance: Mr Lei Zhu, Mr Xin Quan, Mr Bing Xia, Mr Yafeng Yang, Mr Teng Ma, Ms Lifeng Lan, Ms Chunmei Wang, Mr Haifeng Zhang, Ms Jing Fan, and Mr Yongqiang Li.

\section{Disclosure}

The authors report no conflicts of interest in this work.

\section{References}

1. Sulaiman OA, Gordon T. Effects of short- and long-term schwann cell denervation on peripheral nerve regeneration, myelination, and size. Glia. 2000;32(3):234-246.

2. Pabari A, Yang SY, Mosahebi A, et al. Recent advances in artificial nerve conduit design: strategies for the delivery of luminal fillers. J Control Release. 2011;156(1):2-10.

3. Jaquet JB, Luijsterburg AJ, Kalmijn S, et al. Median, ulnar, and combined median-ulnar nerve injuries: functional outcome and return to productivity. J Trauma. 2001;51(4):687-692.

4. Jiang X, Lim SH, Mao HQ, et al. Current applications and future perspectives of artificial nerve conduits. Exp Neurol. 2010;223(1):86-101.
5. Hu X, Huang J, Ye Z, et al. A novel scaffold with longitudinally oriented microchannels promotes peripheral nerve regeneration. Tissue Eng Part A. 2009;15(11):3297-3308.

6. Cao J, Sun C, Zhao H, et al. The use of laminin modified linear ordered collagen scaffolds loaded with laminin-binding ciliary neurotrophic factor for sciatic nerve regeneration in rats. Biomaterials. 2011;32(16): 3939-3948.

7. Krick K, Tammia M, Martin R, et al. Signaling cue presentation and cell delivery to promote nerve regeneration. Curr Opin Biotechnol. 2011; 22(5):741-746.

8. Lago N, Casas C, Muir EM, et al. Effects of schwann cell transplants in an experimental nerve amputee model. Restor Neurol Neurosci. 2009; 27(1):67-78.

9. Rodriguez FJ, Verdu E, Ceballos D, et al. Nerve guides seeded with autologous schwann cells improve nerve regeneration. Exp Neurol. 2000; 161(2):571-584.

10. Chen ZL, Yu WM, Strickland S. Peripheral regeneration. Annu Rev Neurosci. 2007;30:209-233.

11. Zhang YG, Sheng QS, Qi FY, et al. Schwann cell-seeded scaffold with longitudinally oriented micro-channels for reconstruction of sciatic nerve in rats. J Mater Sci Mater Med. 2013;24(7):1767-1780.

12. Novikova LN, Pettersson J, Brohlin M, et al. Biodegradable poly-betahydroxybutyrate scaffold seeded with schwann cells to promote spinal cord repair. Biomaterials. 2008;29(9):1198-1206.

13. Yeh CW, Wang LW, Wu HC, et al. Development of biomimetic micropatterned device incorporated with neurotrophic gradient and supportive schwann cells for the applications in neural tissue engineering. Biofabrication. 2017;9(1):015024.

14. Goulart CO, Jurgensen S, Souto A, et al. A combination of schwann-cell grafts and aerobic exercise enhances sciatic nerve regeneration. PLoS One. 2014;9(10):e110090.

15. Luo L, Gan L, Liu Y, et al. Construction of nerve guide conduits from cellulose/soy protein composite membranes combined with schwann cells and pyrroloquinoline quinone for the repair of peripheral nerve defect. Biochem Biophys Res Commun. 2015;457(4):507-513.

16. He J, Ding WL, Li F, et al. Panaxydol treatment enhances the biological properties of schwann cells in vitro. Chem Biol Interact. 2009; 177(1):34-39.

17. Sapir Y, Cohen S, Friedman G, et al. The promotion of in vitro vessellike organization of endothelial cells in magnetically responsive alginate scaffolds. Biomaterials. 2012;33(16):4100-4109.

18. Sapir Y, Polyak B, Cohen S. Cardiac tissue engineering in magnetically actuated scaffolds. Nanotechnology. 2014;25(1):014009.

19. Zhang J, Zhao S, Zhu M, et al. 3d-printed magnetic fe $304 / \mathrm{mbg} / \mathrm{pcl}$ composite scaffolds with multifunctionality of bone regeneration, local anticancer drug delivery and hyperthermia. J Mater Chem B. 2014; 2(43):7583-7595.

20. Meng J, Xiao B, Zhang Y, et al. Super-paramagnetic responsive nanofibrous scaffolds under static magnetic field enhance osteogenesis for bone repair in vivo. Sci Rep. 2013;3:2655.

21. Zhang N, Lock J, Sallee A, et al. Magnetic nanocomposite hydrogel for potential cartilage tissue engineering: synthesis, characterization, and cytocompatibility with bone marrow derived mesenchymal stem cells. ACS Appl Mater Interfaces. 2015;7(37):20987-20998.

22. Liu Z, Huang L, Liu L, et al. Activation of schwann cells in vitro by magnetic nanocomposites via applied magnetic field. Int J Nanomedicine. 2015;10:43-61.

23. Hsu SH, Chan SH, Chiang CM, et al. Peripheral nerve regeneration using a microporous polylactic acid asymmetric conduit in a rabbit long-gap sciatic nerve transection model. Biomaterials. 2011;32(15): 3764-3775.

24. Riggio C, Calatayud MP, Hoskins C, et al. Poly-1-lysine-coated magnetic nanoparticles as intracellular actuators for neural guidance. Int $J$ Nanomed. 2012;7:3155-3166.

25. Bai WF, Xu WC, Feng Y, et al. Fifty-hertz electromagnetic fields facilitate the induction of rat bone mesenchymal stromal cells to differentiate into functional neurons. Cytotherapy. 2013;15(8):961-970. 
26. Zhang Y, Ding J, Duan W. A study of the effects of flux density and frequency of pulsed electromagnetic field on neurite outgrowth in pc12 cells. J Biol Phys. 2006;32(1):1-9.

27. Trillo MA, Martinez MA, Cid MA, et al. Retinoic acid inhibits the cytoproliferative response to weak $50 \mathrm{hz}$ magnetic fields in neuroblastoma cells. Oncol Rep. 2013;29(3):885-894.

28. Mey J, Schrage K, Wessels I, et al. Effects of inflammatory cytokines il-1beta, il-6, and tnfalpha on the intracellular localization of retinoid receptors in schwann cells. Glia. 2007;55(2):152-164.

29. Zhu S, Ge J, Wang Y, et al. A synthetic oxygen carrier-olfactory ensheathing cell composition system for the promotion of sciatic nerve regeneration. Biomaterials. 2014;35(5):1450-1461.

30. Hare GM, Evans PJ, Mackinnon SE, et al. Walking track analysis: a long-term assessment of peripheral nerve recovery. Plast Reconstr Surg. 1992;89(2):251-258.

31. Lassenberger A, Scheberl A, Stadlbauer A, et al. Individually stabilized, superparamagnetic nanoparticles with controlled shell and size leading to exceptional stealth properties and high relaxivities. ACS Appl Mater Interfaces. 2017;9(4):3343-3353.

32. Jain TK, Richey J, Strand M, et al. Magnetic nanoparticles with dual functional properties: drug delivery and magnetic resonance imaging. Biomaterials. 2008;29(29):4012-4021.

33. Lee JH, Jang JT, Choi JS, et al. Exchange-coupled magnetic nanoparticles for efficient heat induction. Nat Nanotechnol. 2011;6(7):418-422.

34. Szlezak M, Nieciecka D, Joniec A, et al. Monoolein cubic phase gels and cubosomes doped with magnetic nanoparticles-hybrid materials for controlled drug release. ACS Appl Mater Interfaces. 2017;9(3): 2796-2805.

35. Cornell RM, Schwertmann U. The Iron Oxides: Structure, Properties, Reactions, Occurrences and Uses. Hoboken, NJ: John Wiley \& Sons; 2003.

36. Crompton KE, Goud JD, Bellamkonda RV, etal. Polylysine-functionalised thermoresponsive chitosan hydrogel for neural tissue engineering. Biomaterials. 2007;28(26):441-449.

37. Harley BA, Hastings AZ, Yannas IV, et al. Fabricating tubular scaffolds with a radial pore size gradient by a spinning technique. Biomaterials. 2006;27(6):866-874.
38. Plikk P, Malberg S, Albertsson AC. Design of resorbable porous tubular copolyester scaffolds for use in nerve regeneration. Biomacromolecules. 2009;10(5):1259-1264.

39. Tansey KE, Seifert JL, Botterman B, et al. Peripheral nerve repair through multi-luminal biosynthetic implants. Ann Biomed Eng. 2011;39(6): 1815-1828.

40. Goldner JS, Bruder JM, Li G, et al. Neurite bridging across micropatterned grooves. Biomaterials. 2006;27(3):460.

41. Kim YT, Haftel VK, Kumar S, et al. The role of aligned polymer fiber-based constructs in the bridging of long peripheral nerve gaps. Biomaterials. 2008;29(21):3117-3127.

42. Bozkurt A, Deumens R, Beckmann C, et al. In vitro cell alignment obtained with a schwann cell enriched microstructured nerve guide with longitudinal guidance channels. Biomaterials. 2009;30(2):169-179.

43. Tampieri A, Landi E, Valentini F, et al. A conceptually new type of bio-hybrid scaffold for bone regeneration. Nanotechnology. 2011;22(1): 015104.

44. Bettinger CJ, Bruggeman JP, Misra A, et al. Biocompatibility of biodegradable semiconducting melanin films for nerve tissue engineering. Biomaterials. 2009;30(17):3050-3057.

45. Chouly C, Pouliquen D, Lucet I, et al. Development of superparamagnetic nanoparticles for mri: effect of particle size, charge and surface nature on biodistribution. J Microencapsul. 1996;13(3):245-255.

46. Gupta AK, Wells S. Surface-modified superparamagnetic nanoparticles for drug delivery: preparation, characterization, and cytotoxicity studies. IEEE Trans Nanobioscience. 2004;3(1):66-73.

47. Sun F, Zhou K, Mi WJ, et al. Combined use of decellularized allogeneic artery conduits with autologous transdifferentiated adipose-derived stem cells for facial nerve regeneration in rats. Biomaterials. 2011;32(32): 8118-8128.

48. Zhang N, Lock J, Sallee A, et al. Magnetic nanocomposite hydrogel for potential cartilage tissue engineering: synthesis, characterization, and cytocompatibility with bone marrow derived mesenchymal stem cells. ACS Appl Mater Interfaces. 2015;7(37):20987-20998.
International Journal of Nanomedicine

\section{Publish your work in this journal}

The International Journal of Nanomedicine is an international, peerreviewed journal focusing on the application of nanotechnology in diagnostics, therapeutics, and drug delivery systems throughout the biomedical field. This journal is indexed on PubMed Central, MedLine, CAS, SciSearch ${ }^{\circledR}$, Current Contents ${ }^{\circledR} /$ Clinical Medicine,

\section{Dovepress}

Journal Citation Reports/Science Edition, EMBase, Scopus and the Elsevier Bibliographic databases. The manuscript management system is completely online and includes a very quick and fair peer-review system, which is all easy to use. Visit http://www.dovepress.com/ testimonials.php to read real quotes from published authors. 